\title{
Más allá de los controles de capital: regulación de los mercados de derivados en moneda extranjera en la República de Corea y el Brasil después de la crisis financiera mundial
}

\author{
Daniela Magalhães Prates y Barbara Fritz
}

RESUMEN

En el marco de la gestión de los flujos de capital, algunas economías emergentes han afrontado, después de la crisis mundial, dilemas en términos de políticas económicas relacionados con las operaciones de instrumentos financieros, en un contexto de abundante liquidez actual en las economías avanzadas. Sin embargo, la regulación de los derivados en moneda extranjera en las economías emergentes no ha sido suficientemente tratada ni en la literatura, ni por las instituciones financieras. Aquí se analizan las medidas aplicadas en el Brasil y la República de Corea. Primero, se constata que la amplitud de las regulaciones a las operaciones de derivados en moneda extranjera depende de los agentes y del tipo de contrato. Segundo, se requiere una institucionalidad interna eficaz para la formulación y aplicación de regulaciones. Tercero, los países no debieran limitar su margen normativo mediante acuerdos multilaterales o bilaterales, y dejar espacio para la regulación financiera interna.

PALABRAS CLAVE

CLASIFICACIÓN JEL

AUTORES
Movimientos de capital, control de cambios, valores de derivados, divisas, crisis financiera, República de Corea, Brasil

F36, F41
Daniela Magalhães Prates es Profesora Asociada del Instituto de Economía de la Universidad Estatal de Campinas, Brasil. danimagaprates@gmail.com

Barbara Fritz es Profesora Titular del Instituto de Estudios Latinoamericanos de la Freie Universität de Berlín, Alemania. Barbara.Fritz@fu-berlin.de 


\section{I}

\section{Introducción}

Las economías emergentes han tenido que hacer frente a los problemas derivados de su propio éxito ${ }^{1}$. No solo poseen tasas de ocupación y de crecimiento superiores a las de los países miembros de la Organización para la Cooperación y el Desarrollo Económicos (OCDE), sino que se han recuperado rápidamente de la crisis financiera que se desencadenó a partir de la cesación de pagos de Lehman Brothers ocurrida en 2008. Por consiguiente, desde mediados de 2009, las economías emergentes han experimentado un nuevo auge de las entradas de capital, aunque este haya sido muy inestable. Muchos gobiernos están cada vez más preocupados por los inconvenientes de esas entradas. Consideran que la dependencia de flujos de capital muy volátiles constituye una amenaza a la estabilidad financiera a corto plazo y, en sentido más general, a su espacio para políticas económicas nacionales.

Al mismo tiempo, el debate sobre los controles de capital, que desde hace tiempo había quedado relegado por considerarse anacrónico, se ha vuelto a establecer con gran fuerza en la agenda política y académica (Gallagher, Griffith-Jones y Ocampo, 2012; Jeanne, Subramanian y Williamson, 2012; Fritz y Magalhães Prates, 2014). Incluso el Fondo Monetario Internacional (FMI), que durante muchos años fue hostil a cualquier tipo de régimen de control de capital, está participando en un nuevo debate sobre la gestión de los flujos de capital (FMI, 2012b). Sin embargo, las instituciones financieras internacionales y muchos académicos no estaban bien preparados para ese debate. Como afirma Rodrik (2010, pág. 2): "Actualmente no sabemos mucho acerca del diseño de regímenes de control de capital. El tabú [que se ha] asociado a los controles de capital ha entorpecido la realización de labores prácticas y de orientación normativa que contribuyan a gestionar directamente los flujos de capital".

Además de la gestión de los flujos de capital, en algunas economías emergentes también se han afrontado dilemas de políticas económicas relacionados con operaciones de derivados en moneda extranjera realizadas

\footnotetext{
1 En el presente documento, el término "economías emergentes" se refiere a los países en desarrollo que han emprendido la globalización financiera. Por consiguiente, no se emplea la definición del Fondo Monetario Internacional (FMI), en la que se clasifica a la República de Corea como nueva economía avanzada.
}

por extranjeros (no residentes) y por nacionales (residentes). En un entorno de abundante liquidez y tasas de interés históricamente bajas en las economías avanzadas, los inversionistas extranjeros que buscan rendimiento a corto plazo, así como los agentes nacionales, a menudo obtienen grandes ganancias de los diferenciales de las tasas de interés entre las economías avanzadas y las emergentes. Sin embargo, la regulación de los derivados en divisas en las economías emergentes no ha recibido la debida atención, ni en la bibliografía académica ni en las instituciones financieras internacionales, aunque dicha regulación podría resultar decisiva para las economías emergentes de alto grado de apertura financiera y liquidez, así como para grandes mercados de derivados en moneda extranjera, como los del Brasil y la República de Corea.

Como señalan Mihaljek y Packer (2010, pág. 51), el Brasil y la República de Corea tienen los mayores mercados de instrumentos financieros derivados en moneda extranjera entre las economías emergentes. Esa característica, combinada con una política de no intervención en las entradas de capital, pareció intensificar el efecto de contagio de la crisis financiera mundial en las monedas y los mercados financieros de ambos países, a pesar de los superávits en cuenta corriente que habían registrado hasta 2007 y de sus enormes reservas internacionales (Prates y Cintra, 2010).

El Brasil y la República de Corea (al igual que otras economías emergentes) han aprendido lecciones muy difíciles de la crisis mundial, la que demostró que la acumulación de reservas no era protección suficiente contra los efectos adversos de los flujos de capital volátiles y las operaciones especulativas en los mercados de derivados en moneda extranjera. Desde 2009, ambos países han recurrido a los controles de capital y la regulación financiera prudencial para hacer frente al nuevo auge de los flujos de capital hacia las economías emergentes ${ }^{2}$. Esos y otros instrumentos normativos se están utilizando también para poner freno a las transacciones con derivados en moneda extranjera realizadas por agentes residentes o no residentes.

\footnotetext{
2 Además del Brasil y la República de Corea, los principales receptores de entradas de capital en el período de auge posterior a la crisis de los flujos de capital han sido Sudáfrica, el Perú, Tailandia, Indonesia y Turquía. Véanse más detalles en FMI (2011a).
} 
En este documento se analizan los enfoques aplicados por el Brasil y la República de Corea respecto de la regulación de derivados en moneda extranjera a raíz de la crisis financiera mundial. La regulación de las operaciones en los mercados internos de derivados en moneda extranjera resulta difícil de evaluar con métodos econométricos, pues en el análisis han de tenerse en cuenta la coincidencia y la interdependencia, en períodos muy breves, de factores como los que se enumeran a continuación: i) frecuentes conmociones externas, dada la inestabilidad del entorno mundial y la gran volatilidad de los flujos de capital internacionales; ii) períodos muy cortos; iii) cambios normativos macroeconómicos, sobre todo en lo que se refiere a políticas monetarias y cambiarias, y iv) frecuentes cambios normativos a nivel nacional. Por consiguiente, en el análisis aquí expuesto se incorporan métodos cualitativos y análisis estadísticos descriptivos.

En contraste con las evaluaciones empíricas, el presente documento se centra en la especificidad de la regulación sobre los derivados de divisas en el Brasil y la República de Corea. Se parte de la hipótesis de que ese tipo de regulación se distingue de los controles de capital y la regulación financiera prudencial, que tienen que ajustarse en función del marco institucional específico de cada país para poder abarcar esa clase de transacciones financieras y tener en cuenta tanto a los agentes no residentes como a los residentes.

Con este artículo se pretende hacer un aporte al debate sobre la regulación financiera proveniente de la crisis mundial. Se reconoce que existe un consenso cada vez mayor sobre la necesidad de aplicar un enfoque más sistémico a las políticas macroeconómicas, monetarias y financieras (Blanchard, Dell'Ariccia y Mauro, 2010; Eichengreen y otros, 2011), en contraste con las políticas en que solo se prioriza la estabilización de los niveles de precios. No obstante, el debate sobre la regulación de los flujos internacionales de capital (en particular los derivados en moneda extranjera en las economías emergentes) dista mucho de estar consolidado en términos teóricos y en lo que se refiere a las recomendaciones de política económica.

En la sección II se establece un enfoque amplio respecto de la regulación financiera, sobre la base de un examen de las tipologías de la regulación de los flujos de capital. De ese modo es posible analizar enfoques normativos específicos para cada país. En las economías emergentes caracterizadas por un alto grado de apertura financiera y mercados financieros internos sofisticados, como es el caso de los países objeto de este análisis, esos mercados y los flujos transfronterizos están profundamente entrelazados. En consecuencia, aquí se afirma que ya no es útil ni posible la división analítica, que suele adoptarse en la bibliografía, entre la regulación financiera interna y externa. En ese entorno, la regulación financiera prudencial, los controles de capital y otras medidas normativas (como la regulación de los mercados de derivados en moneda extranjera) deberían considerarse parte esencial del conjunto de instrumentos de regulación financiera. En la sección III se analizan las experiencias de la República de Corea y del Brasil. En la cuarta sección se exponen conclusiones generales derivadas del estudio de esos casos particulares.

\section{II \\ Un criterio amplio respecto de las regulaciones financieras}

La bibliografía académica sobre la regulación de los flujos de capital por parte de las economías emergentes (es decir, la regulación financiera externa) ha proliferado desde la década de 1990 y adquirió un mayor impulso después de la crisis financiera mundial, con lo que se elaboraron distintas tipologías.

Dados el volumen y la volatilidad de esas corrientes y sus consecuencias potencialmente perjudiciales para las economías emergentes, el FMI ha dado un giro decidido a su posición oficial sobre la evaluación de los controles de capital (FMI, 2010, 2011a y 2012b; Ostry y otros, 2010 y 2011a), con la consiguiente adopción por ese organismo de una nueva visión institucional (FMI, 2011a y 2012b). En esos documentos recientes, el conjunto de instrumentos concebidos para influir en las entradas de capital es denominado como "medidas de administración de los flujos de capital", que se definen como la suma de las medidas establecidas para ralentizar la apreciación de los tipos de cambio o desviar esos flujos a otros países. Entre otras medidas, incluye 
aquellas en las que se hace distinción entre la condición de residente y entre las denominaciones de las monedas, además de otras regulaciones consistentes, por ejemplo, en períodos mínimos de tenencia e impuestos sobre inversiones concretas que suelen aplicarse en el sector no financiero (FMI, 2011a, págs. 6 y 40f).

En el entorno académico, el debate comenzó con anterioridad. En orden cronológico, Epstein, Grabel y Jomo (2004) utilizan el término "técnicas de gestión del capital" para referirse a dos tipos complementarios de regulaciones financieras, que influyen en los flujos de capital y que tienen cierto grado de coincidencia entre sí. Se trata de las políticas por las que se rigen los flujos internacionales de capital privado, denominados "controles de capital", y en las que se basa la gestión prudencial de las instituciones financieras nacionales. En su definición se tiene en cuenta el hecho de que algunos instrumentos de regulación financiera prudencial funcionan en la práctica como controles de capital, mientras que otros contribuyen a reducir los riesgos financieros sistémicos. Ocampo (2012) y Gallagher, Griffith-Jones y Ocampo (2012) prefieren el término "regulaciones de la cuenta de capital" (RCC) para subrayar el hecho de que esas regulaciones sobre los flujos de capital pertenecen a la familia más amplia de las regulaciones financieras y no solo deberían abarcar las entradas, sino las salidas y los instrumentos basados en los precios o basados en factores cuantitativos. Priewe (2011) propone el concepto de "manejo de la cuenta de capital", que abarca todas las formas mediante las que las autoridades podrían tener una influencia (in)directa en los flujos de capital y las cuentas de capital, a saber: la política monetaria y fiscal soberana, la gestión de los tipos de cambio, las regulaciones del sector financiero nacional, las regulaciones relacionadas con inversión extranjera directa (IED), controles directos de capital y normas internacionales, y la intervención coordinada para estabilizar los tipos de cambio.

A pesar de las diferencias conceptuales, sobre todo entre el criterio del FMI y los demás enfoques, todos los teóricos reconocen cuatro preceptos clave ${ }^{3}$. En primer lugar, la regulación de los flujos de capital debe abarcar políticas multifacéticas (controles de capital y regulaciones prudenciales), pues no basta con una sola medida para lograr objetivos diversos. En segundo lugar, a menudo no se puede mantener en la práctica una bifurcación estricta entre esas políticas (Epstein, Grabel y Jomo, 2004; Ocampo, 2012). En tercer lugar, suele haber un

3 Véase un análisis crítico del nuevo enfoque del FMI en Fritz y Magalhães Prates (2014), y Gallagher (2012). alto grado de sinergia y coincidencia entre esas medidas. En particular, Epstein, Grabel y Jomo (2004, pág. 6) señalan que "la eficacia de cualquier técnica de gestión por sí sola contribuye a potenciar la eficacia de otras técnicas y la eficiencia de todo el régimen de gestión del capital. Por ejemplo, determinadas regulaciones financieras prudenciales potencian la eficacia de los controles de capital (y viceversa). En este caso, el aspecto estabilizador de la regulación prudencial hace menos necesaria la forma más rigurosa de control de capital. Así, un programa de técnicas complementarias de gestión de capital reduce el rigor necesario de cualquier técnica en particular y potencia la eficacia del régimen de control financiero". Por último, también hay retroalimentaciones entre esas dos regulaciones (las regulaciones financieras prudenciales y los controles de capital) y la política macroeconómica.

Además, en las economías emergentes que tienen un alto grado de apertura financiera y mercados financieros nacionales sofisticados, esos mercados y flujos transfronterizos están profundamente entrelazados. En consecuencia, la división analítica tradicional (que suele adoptarse en la bibliografía) entre la regulación financiera interna y externa, ya no es útil ni posible. Por lo tanto, la regulación financiera en las economías emergentes que presentan esas características debería considerarse en un sentido más amplio, sin hacer distinción entre sus dimensiones interna y externa. Las regulaciones financieras prudenciales, los controles de capital y otras medidas normativas (como la regulación de los mercados de derivados) deberían considerarse parte esencial del conjunto de instrumentos de regulación financiera aplicables a los residentes y no residentes, así como a los agentes financieros y no financieros, con respecto a sus decisiones de cartera en moneda extranjera y nacional, y en los mercados al contado y de derivados (liquidación a término).

Ese conjunto de instrumentos debería adaptarse a las condiciones propias de cada país y estar configurado por el contexto local en función del grado de apertura financiera, el marco institucional del sistema financiero y las metas del país en materia normativa. En el caso de las economías emergentes, los objetivos más importantes consisten en reducir los riesgos y aumentar el margen normativo como parte de las iniciativas encaminadas a controlar importantes precios macroeconómicos, como el tipo de cambio y la tasa de interés, sobre todo con el fin de permitir la adopción de políticas anticíclicas que hagan posible mitigar los efectos de auge y desplome de los flujos de capital y el apetito de riesgo de los inversores mundiales. Entre ambos objetivos 
hay retroalimentaciones importantes. Por ejemplo, la apreciación de la moneda estimula las posiciones especulativas en derivados en moneda extranjera, lo que pone en peligro la estabilidad financiera. En consecuencia, la capacidad de mantener el tipo de cambio a un nivel competitivo (un objetivo secundario) contribuye a esa estabilidad (el objetivo primario).
En vista de que cada instrumento normativo también está dirigido a determinados agentes y mercados (véase el cuadro 1), cada país puede incluir en su conjunto de instrumentos normativos diversas regulaciones, en función de sus especificidades institucionales y objetivos en materia de políticas. Por lo tanto, es importante definir con claridad cada tipo de instrumento normativo.

CUADRO 1

\section{Conjunto de instrumentos de regulación financiera}

\begin{tabular}{lcc}
\hline & \multicolumn{2}{c}{ Agentes } \\
Regulación & Financieros o no financieros & Residentes o no residentes \\
\cline { 2 - 3 } & Instituciones financieras & Residentes \\
Regulación prudencial & Ambos & Ambos de derivados) \\
Regulación sobre los derivados en divisas & Al contado y de derivados \\
Controles de capital & De derivados \\
Inversión en cartera e IED & Ambos & No residentes \\
Préstamos extranjeros & Ambos & Residentes \\
\hline
\end{tabular}

Fuente: Elaboración propia.

Nota: IED: Inversión extranjera directa.

Las regulaciones financieras prudenciales se refieren a políticas como las normas sobre suficiencia del capital, los requisitos en materia de presentación de informes o las restricciones sobre la capacidad y los términos en que las instituciones financieras nacionales pueden aportar capital a determinados tipos de proyectos. También pueden incluir normas prudenciales en materia de desajustes cambiarios en los balances generales, o restricciones sobre la emisión de determinados tipos de contratos de derivados o a término (Epstein, Grabel y Jomo, 2004). Esas regulaciones solamente influyen en las posiciones de activos y pasivos de las instituciones financieras residentes.

En cuanto a los controles de capital, no hay ninguna definición legal generalmente aceptada. Por consiguiente, aquí se adopta la definición funcional más amplia posible propuesta por Neely (1999), según la que dichos controles se refieren a medidas para gestionar el volumen, la composición o la asignación de los flujos de capital internacionales privados ${ }^{4}$. Los

\footnotetext{
${ }^{4}$ Ostry y otros (2011a, pág. 11) reconocen que no existe una definición única de los controles de capital, pero se ciñen a una definición jurídica presentada por la Organización para la Cooperación y el Desarrollo Económicos (OCDE) en su Código de la OCDE para la Liberalización de los Movimientos de Capital (2009), según la que se considera que los controles de capital solamente están sujetos a las obligaciones en materia de liberalización si discriminan entre residentes y no residentes. En documentos posteriores del FMI sobre este tema también se adopta esa definición. Ahí radica uno de los problemas del nuevo enfoque del
}

controles de capital pueden estar dirigidos a las entradas o las salidas y, por lo general, se refieren a corrientes particulares (como la inversión de cartera, sobre la base de su percepción de riesgos y oportunidades). Además, los controles de capital pueden basarse en la tributación o ser de tipo cuantitativo. Los impuestos financieros o los requisitos de reservas aplicables a determinados tipos de inversiones son ejemplo de controles basados en la tributación. Entre los controles de capital cuantitativos se incluyen prohibiciones directas de determinadas inversiones (por ejemplo, la compra de valores por inversores extranjeros), las restricciones o cuotas, o los requisitos para la concesión de licencias (Epstein, Grabel y Jomo, 2004). En otras palabras, los controles de capital constituyen un abanico de instrumentos de regulación financiera que permiten gestionar los flujos transfronterizos (tanto las entradas como las salidas) relacionados con los inversores extranjeros y las empresas y bancos residentes. A diferencia de las regulaciones financieras prudenciales, pueden influir en las decisiones de cartera que adopten las instituciones no financieras residentes y los agentes no residentes.

Además de las medidas financieras prudenciales y los controles de capital, puede necesitarse un tercer tipo

FMI. En aras de la no discriminación, los controles de capital definidos de esa manera deberían aplicarse únicamente en última instancia. El FMI ha introducido una jerarquía de medidas en lugar de centrarse en la adecuación y la eficiencia de las regulaciones existentes. 
de regulación para poner freno a los riesgos financieros y aumentar el margen normativo en las economías emergentes con mercados abiertos y sofisticados de derivados en moneda extranjera, en función de las características institucionales de esos mercados. Por una parte, la regulación financiera prudencial tal vez no sea suficiente para influir en las operaciones con derivados en moneda extranjera, puesto que solo afecta a los balances generales de las instituciones financieras; en consecuencia, las operaciones con derivados en moneda extranjera realizadas por inversores no residentes y agentes residentes no financieros quedan fuera del ámbito de aplicación de esa clase de regulaciones. Por otra parte, los controles de capital influyen solo en las transacciones transfronterizas y, por lo tanto, no abarcan las operaciones con derivados en moneda extranjera en el mercado interno. Incluso en el caso de operaciones realizadas por inversores extranjeros, los controles de capital no son el tipo de regulación más adecuado y eficaz, pues no surtirían más que un escaso efecto si se aplicaran, por ejemplo, a una entrada de capital relacionada con el pago del costo de una operación de derivados, como pueden ser los depósitos de garantía mínimos sobre los contratos de futuros. Una característica importante de los derivados financieros en su conjunto es su alto grado de apalancamiento, en el sentido de que para su realización solo exigen un depósito de garantía mínimo o el pago de una prima. A su vez, esa característica específica hace que los derivados en moneda extranjera sean un instrumento privilegiado para la especulación monetaria y la obtención de ganancias mediante los diferenciales de las tasas de interés. Además, es posible que esas entradas ni siquiera tengan lugar: en las economías emergentes con mercados financieros abiertos, los inversores extranjeros suelen tener inversiones en otros activos que podrían liquidar y transferir para sufragar ese costo. En el presente documento, esa tercera clase de reglamentación se denominará regulaciones sobre los derivados de divisas, centrada en la regulación de las operaciones realizadas por residentes y no residentes con ese instrumento de liquidación a término en el mercado interno (véase el cuadro 1).

\section{III}

\section{Estudios de caso}

Desde 2008, la mayoría de las economías avanzadas se han caracterizado por la turbulencia financiera y las recesiones abruptas o el escaso crecimiento, en tanto que la mayoría de las economías emergentes y algunos países en desarrollo han navegado con mucha más suerte en sentido financiero y económico (Ocampo, 2012; Canuto y Giugale, 2010; Canuto y Leipziger, 2012).

En respuesta a esas condiciones, en las economías avanzadas se aplicaron políticas de flexibilización cuantitativa, que permitieron generar abundante liquidez y tasas de interés bajas y desencadenar, a partir del segundo trimestre de 2009, un nuevo auge de los flujos de capital hacia las economías emergentes. De ello se deduce que ese nuevo período de auge (el cuarto en la era posterior a Bretton Woods) fue motivado por las circunstancias heredadas de la crisis. Esas corrientes perdieron cierto impulso después de mayo de 2013, cuando la Reserva Federal de los Estados Unidos de América indicó que tal vez comenzaría a reducir gradualmente su política de flexibilización cuantitativa hacia finales del año civil. No obstante, es de suponer que los mercados emergentes experimentarán un período prolongado de grandes entradas de capital (Akyüz, 2011; BPI, 2010; Canuto y Leipziger, 2012).

Al igual que antes de la crisis, las monedas y los activos de varios países emergentes han vuelto una vez más a ser blanco de las carry trade u operaciones de acarreo (debido a los diferenciales de las tasas de interés) y otros flujos de capital. La combinación resultante de altas tasas de crecimiento, aceleración de la inflación (que también se asocia con un nuevo auge de los precios de los productos básicos), apreciación excesiva de la moneda o sobreajuste del precio de los activos ha entrañado dilemas normativos para las economías emergentes (Akyüz, 2011; BPI, 2010). Ante esa situación, la adopción de una política monetaria restrictiva contribuiría a contener el crecimiento y las presiones inflacionarias, pero alentaría nuevas entradas de capital que, a su vez, promoverían el alza de los precios de los activos y el desajuste de los tipos de cambio, lo que agravaría el riesgo de interrupciones repentinas en el futuro, con las subsiguientes crisis financieras. A fin de hacer frente a esos dilemas, en muchas economías emergentes se ha recurrido a los controles de capital y 
las regulaciones financieras prudenciales. A diferencia del contexto anterior a la crisis, muchos de esos países no están dispuestos a volver a adoptar una política de no intervención respecto de las entradas de capital.

Sin embargo, las experiencias de los países tanto antes de la crisis financiera mundial (Ariyoshi y otros, 2000; Herr y Priewe, 2006; Magud, Reinhart y Rogoff, 2011) como después de ella (Klein, 2012; FMI, 2011a; Fritz y Magalhães Prates, 2014; Baumann y Gallagher, 2012 y 2013) indican que el diseño del conjunto de instrumentos de reglamentación financiera es un proceso sumamente complejo, pues está configurado por un conjunto de factores macroeconómicos, institucionales y estructurales, como el grado de apertura financiera, la composición de los flujos de capital, las características de los mercados financieros y monetarios, y los correspondientes objetivos en materia de política.

Las experiencias del Brasil y la República de Corea, los dos estudios de caso presentados en este documento, ponen de relieve esa complejidad. En esos países se aplicaron estrategias muy similares en cuanto a la gestión de los flujos de capital entre 2003-2007, con una inversión excesiva en la costosa acumulación de reservas y una inversión insuficiente en políticas de gestión de las cuentas de capital (Rodrik, 2006, pág. 12). Sin embargo, al igual que en otras economías emergentes, los encargados de la formulación de políticas en el Brasil y la República de Corea extrajeron enseñanzas de la crisis financiera mundial, pues se dieron cuenta de que esa estrategia no los protegió de los efectos perjudiciales de la propensión a asumir riesgos excesivos por las instituciones financieras nacionales, ni de la apreciación excesiva de la moneda, ocasionada por los flujos de capital y las operaciones con derivados en moneda extranjera.

Ante el renovado apetito de riesgo de los inversores mundiales por los activos y las monedas de las economías emergentes desde 2009, en los dos países se han adoptado diversas medidas regulatorias en procura de soluciones a los dilemas normativos y con el fin de evitar que esos desequilibrios vuelvan a surgir. En ambos países se impuso la obligación de adoptar regulaciones específicas dirigidas a las operaciones con derivados en moneda extranjera, además de las regulaciones encaminadas a frenar los flujos de capital, debido a cómo influye en la tendencia de los tipos de cambio o en la situación financiera de los bancos y corporaciones en las dos economías. En las dos subsecciones siguientes se detallan las regulaciones aplicadas por el Brasil y la República de Corea, a fin de poner coto a las estrategias de asunción de riesgos mediante operaciones con derivados en moneda extranjera, con variantes en cada país debido a las características institucionales diferentes de sus mercados de dichos instrumentos ${ }^{5}$.

\section{República de Corea}

Tras la crisis de 1997, el Gobierno de la República de Corea decidió aumentar la apertura financiera del país. Como señalan Kim y Yong Yang (2010), se desmantelaron la mayoría de las restricciones sobre los flujos de capital y, como también sucedió en el Brasil, las entradas y salidas de capital pasaron a estar determinadas por el mercado. Durante el auge de los movimientos entre 2003 y 2007, en la República de Corea se inició un proceso de acumulación de reservas y los controles sobre la inversión en el exterior se fueron tornando progresivamente más flexibles con el fin de frenar las presiones a la apreciación; como resultado de ello, hacia 2007 se habían eliminado la mayoría de los controles (Baba y Kokenyne, 2011).

La reanudación de las entradas después de la crisis financiera mundial comenzó con las corrientes de inversiones de cartera en los mercados de deuda y de capitales, y se basó en factores tanto externos (las circunstancias posteriores a la crisis) como internos (la rápida recuperación económica y la sólida situación macroeconómica de la República de Corea). Sin embargo, la deuda bancaria a corto plazo se mantuvo por debajo de los niveles del período anterior a la crisis, gracias a la estrategia de regulación financiera puesta en marcha por las autoridades coreanas después de noviembre de 2009 para enfrentar el nuevo auge de los flujos de capital (véase el cuadro 2). A su vez, esa estrategia estuvo determinada por el enorme efecto de contagio que tuvo la crisis financiera mundial en el sistema bancario coreano ${ }^{6}$.

De modo similar al Brasil, la drástica devaluación de la moneda coreana (el won) estuvo asociada con las operaciones con derivados en moneda extranjera realizadas por las empresas. El sobreajuste del tipo de cambio entre el won y el dólar (véase el gráfico 1) entre agosto de 2007 y octubre de 2008 fue el resultado de la relación entre las operaciones con derivados en moneda extranjera realizadas en los mercados extrabursátiles

\footnotetext{
5 Dado que el presente análisis se centra en las operaciones con derivados en moneda extranjera, la regulación de los flujos de capital se presenta a grandes rasgos en este documento. Véase en FMI (2011a), y Fritz y Magalhães Prates (2014) un análisis detallado de esas regulaciones en el Brasil y la República de Corea después de la crisis financiera mundial.

6 En 2009, el gobierno dio inicio a un plan de rescate valorado en 130.000 millones de dólares con miras a estabilizar el mercado financiero nacional, y en especial el mercado de divisas, ante los enormes pasivos en moneda extranjera que tenían los bancos (Prates y Cintra, 2010).
} 
CUADRO 2

República de Corea: conjunto de instrumentos de regulación financiera

\begin{tabular}{|c|c|c|}
\hline Fecha & Número y tipo & Medida \\
\hline Noviembre de 2009 & Primera PR & $\begin{array}{l}\text { - Normas más exigentes en materia de liquidez en moneda extranjera, con el fin de reducir } \\
\text { el desfase entre los vencimientos de los activos y pasivos en moneda extranjera de los } \\
\text { bancos y de mejorar la calidad de sus activos líquidos. } \\
\text { - Un límite del } 125 \% \text { (en comparación con los ingresos de exportación subyacentes) sobre } \\
\text { los contratos de intercambio a término en divisas entre los bancos y los exportadores. }\end{array}$ \\
\hline Junio de 2010 & Segunda PR & $\begin{array}{l}\text { - Un límite superior sobre los contratos de derivados en moneda extranjera de los bancos } \\
\text { residentes de no más del } 50 \% \text { y - en el caso de las sucursales de bancos extranjeros- de } \\
\text { no más del } 250 \% \text { de su capital en el mes anterior. } \\
\text { - Un límite sobre los bancos que les permite facilitar solo el } 100 \% \text { de las transacciones } \\
\text { subyacentes en los contratos de liquidación a término con los exportadores (antes se } \\
\text { permitía el } 125 \% \text { ). } \\
\text { - La estipulación de que los préstamos y los valores mantenidos hasta su vencimiento (con } \\
\text { vencimientos de un año o más) en moneda extranjera de los bancos residentes han de } \\
\text { tener una cobertura de al menos el } 100 \% \text { de los empréstitos en moneda extranjera con } \\
\text { vencimientos de más de un año. }\end{array}$ \\
\hline
\end{tabular}

Junio de $2010 \quad$ Primer CC

Un límite sobre la financiación en moneda extranjera que solo se aplica al uso en el extranjero, con algunas excepciones en el caso de fabricantes que son empresas pequeñas y medianas.

Enero de $2010 \quad$ Segundo CC $\quad$ Reintroducción de un impuesto retenido en la fuente del 14\% sobre la adquisición por no residentes de bonos del Tesoro y de estabilización monetaria, de modo que el impuesto se vuelve a poner en consonancia con el gravamen aplicable a los bonos comprados por los residentes. Las empresas extranjeras y los no residentes están sujetos a la retención de impuestos en la fuente, pero se exime a los radicados en países que tienen tratados sobre doble tributación con la República de Corea y a los inversores oficiales.

\begin{tabular}{lll}
\hline Junio de 2011 & Tercera PR & Se imponen límites más estrictos a los derivados en moneda extranjera de los bancos. \\
\hline Agosto de 2011 & Tercer CC & Gravamen sobre los pasivos en moneda extranjera. \\
\hline Noviembre de 2012 & Cuarta PR & Se imponen límites más estrictos a los derivados en moneda extranjera de los bancos. \\
\hline
\end{tabular}

Fuente: Fondo Monetario Internacional (FMI), "Recent Experiences in Managing Capital Inflows. Cross-Cutting Themes and Possible Policy Framework", 2011 [en línea] http://bit.ly/QSqrVQ; M. Pradhan y otros, "Policy responses to capital flows in emerging markets", IMF Staff Discussion Notes, $\mathrm{N}^{\circ}$ 11/10, Washington, D.C., Fondo Monetario Internacional, 2011; Banco de Corea [en línea] http://www. bok.or.kr/ eng/engMain. action; y Reuters.

Nota: CC: Control de capital; PR: Regulación prudencial.

${ }^{\text {a }}$ Fecha del anuncio: medida en vigor desde enero de 2013.

GRÁFICO 1

República de Corea: tipo de cambio nominal y medidas de regulación financiera (En won por dólar)

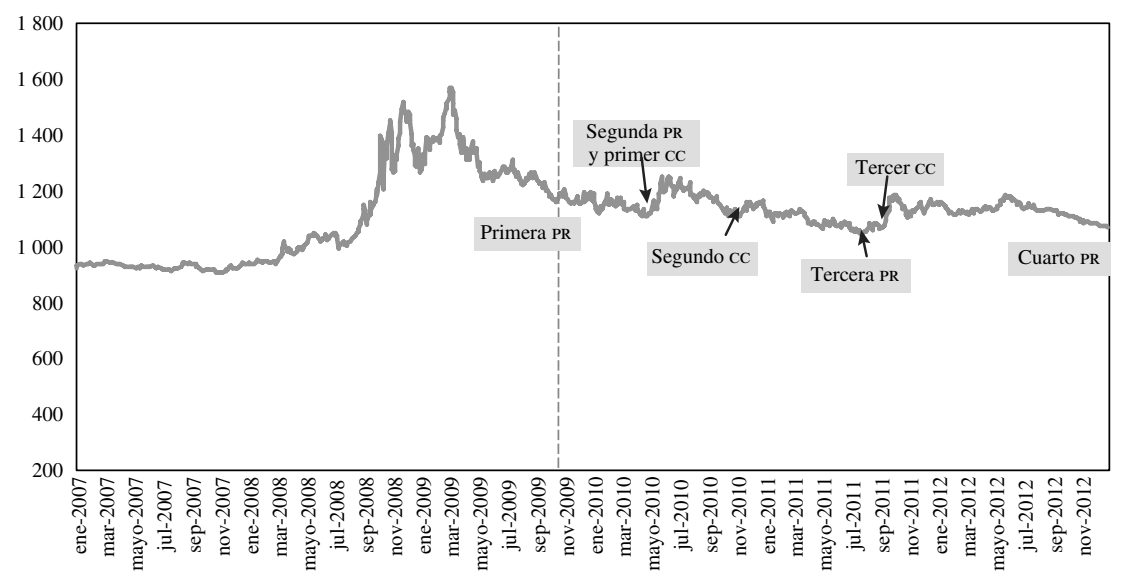

Fuente: Elaboración propia, sobre la base de información de Bloomberg.

Nota: PR: Regulación prudencial; cC: Control de capital. 
de instrumentos financieros - derivados sujetos a la reglamentación nacional - y la elevada deuda a corto plazo contraída por los bancos del país. Ese vínculo estaba relacionado con dos características institucionales del mercado de derivados en moneda extranjera de la República de Corea. En primer lugar, en los mercados extrabursátiles de instrumentos financieros derivados, los bancos cumplen la función de contraparte de sus clientes. En segundo lugar, las ganancias o pérdidas se liquidan en dólares (o sea, son ejecutables), como sucede en la mayoría de los países, pero no en el Brasil.

Antes de la crisis, los bancos vendían a las empresas exportadoras (principalmente de construcción naval) opciones en divisas "knock-in knock-out" (KIKO), un derivado extrabursátil exótico para ofrecer cobertura frente a la apreciación de la moneda nacional en relación con el dólar. Como explica Dodd (2009), esa opción permitió a las empresas vender dólares a un tipo de cambio fijo entre el won y el dólar (es decir, el precio de los dólares de los Estados Unidos de América) si el tipo de cambio fluctuaba dentro de un rango estipulado en el contrato, con lo que se les proporcionaba una posición larga en la moneda nacional. Existían límites a las ganancias potenciales de las empresas sobre las transacciones ( $\mathrm{si}$ se apreciaba el won, dadas sus posiciones largas en esa moneda), en tanto que las pérdidas (si se depreciaba el won) no estaban limitadas, sino que se procuraba que ocurrieran con mayor rapidez (por lo general, dos veces más rápido) con respecto a determinada fluctuación del tipo de cambio subyacente.

Esas empresas comenzaron a realizar operaciones de cobertura de su exposición a las monedas extranjeras en 2004 y aumentaron su razón de cobertura porque preveían una continua apreciación del won. Además, los bancos (principalmente las sucursales locales de bancos extranjeros, que solo estaban sujetas a normas de gestión del riesgo, no a coeficientes de liquidez ni otras regulaciones directas aplicables a los bancos coreanos) practicaron el arbitraje de tasas de interés mediante la obtención de empréstitos en dólares a corto plazo y la venta de esos dólares a cambio de won en el mercado al contado, seguida de la compra de certificados de depósito $\mathrm{u}$ otros bonos nacionales y la venta del won a término a cambio de dólares. En ese contexto de grandes entradas de capital fue que las autoridades liberalizaron progresivamente las salidas de capital (Baba y Kokenyne, 2011; FMI, 2011a).

Con el fin de hacer que las operaciones en el mercado extrabursátil de instrumentos financieros derivados fuesen posibles y rentables, los bancos coreanos y los bancos extranjeros con sucursales en el país obtenían empréstitos en dólares para sostener sus posiciones en ese mercado. Al sobrevenir la crisis y la contracción del crédito en los mercados financieros internacionales, esos bancos no consiguieron refinanciar sus pasivos externos con vencimiento a corto plazo cuando los bancos mundiales redujeron las líneas de crédito para sostener la liquidez. Entonces los bancos coreanos comenzaron a comprar dólares para liquidar sus pasivos externos, lo que impuso presiones tendientes a la devaluación del won. Esa depreciación dio lugar a pérdidas para las empresas que dependían de la apreciación de la moneda y las obligó a entregar a los bancos los dólares correspondientes, que debieron conseguir en parte en el mercado de divisas al contado. Esto impuso una mayor presión a la depreciación del won. Unas 520 pequeñas y medianas empresas de exportación que habían comprado opciones KIKO perdieron unos 2.000 millones de dólares, lo que las llevó al borde de la insolvencia. Varios bancos coreanos locales sufrieron las consecuencias cuando sus clientes los demandaron o se declararon en bancarrota (FMI, 2011a; Kim y Yong Yang, 2010; Dodd, 2009).

De ese modo, el efecto de contagio de la crisis financiera mundial dejó a la vista la importante vulnerabilidad del sistema bancario coreano ante los cambios de las condiciones de financiación a nivel mundial, debido a sus elevados niveles de deuda externa a corto plazo y a los derivados en moneda extranjera conexos, así como al impacto que esas operaciones al contado y con instrumentos derivados tienen en el tipo de cambio. En consecuencia, el conjunto de instrumentos de regulación financiera adoptado por el Gobierno de la República de Corea desde 2009 está encaminado a reducir los riesgos financieros y las fluctuaciones de los tipos de cambio vinculados con los flujos de capital y las operaciones con derivados en moneda extranjera (véase el cuadro 2).

En vista de que los objetivos principales de la regulación financiera eran los niveles de exposición de los bancos a las monedas extranjeras en operaciones al contado y de cambio de divisas a término, las autoridades coreanas establecieron un conjunto de medidas de regulación financiera prudencial después de noviembre de 2009 (véase el cuadro 2), con el objetivo de fortalecer la gestión de la liquidez en moneda extranjera de los bancos y limitar sus contratos de deuda a corto plazo y contratos a término a niveles sostenibles. Las medidas para alcanzar esas posiciones a término en moneda extranjera estaban encaminadas indirectamente a reducir el endeudamiento externo por parte del sector bancario, como había sucedido antes de la crisis. Los bancos coreanos y los bancos extranjeros con sucursales en el 
país obtenían empréstitos en dólares para sostener sus posiciones en el mercado extrabursátil de instrumentos financieros derivados.

Por consiguiente, las medidas de regulación financiera prudencial, que solo se centraron en las posiciones de activos y pasivos de los bancos en el mercado al contado y el mercado a término (véase el cuadro 2), contribuyeron a impedir que la deuda externa volviera a los niveles previos a la crisis y a limitar las operaciones con derivados en moneda extranjera sujetas a la reglamentación nacional. Ambas cuestiones estaban estrechamente vinculadas con las decisiones de cartera de los bancos. De ahí que las medidas ayudaron a proteger el tipo de cambio frente a las presiones a la apreciación ocasionadas por la deuda externa a corto plazo de los bancos.

Desde la adopción de esas primeras medidas de regulación financiera prudencial, el tipo de cambio nominal entre el won y el dólar se ha mantenido nominalmente estable, pues el won solo se ha apreciado en un $0,9 \%$ (véase el gráfico 1$)^{7}$. Ante las nuevas presiones a la apreciación en el último trimestre de 2012 debido a la política monetaria ultraexpansiva del Japón, las autoridades coreanas impusieron límites más estrictos a los instrumentos derivados en moneda extranjera utilizados por los bancos en noviembre de 2012 (Jun y Nam, 2012; véase el cuadro 2).

En algunos estudios empíricos se señala la eficacia del conjunto de instrumentos normativos coreanos. Según Bruno y Shin (2013), la sensibilidad de los flujos de capital hacia la República de Corea frente a las condiciones mundiales disminuyó en el período posterior a la introducción de políticas macroprudenciales en 2010. Baumann y Gallagher (2013) concluyen que los controles coreanos tenían un impacto negativo estadísticamente significativo en la volatilidad de los tipos de cambio. Por su parte, Huh, An y Yang (2013) llegan a la conclusión de que las medidas macroprudenciales de la República de Corea en la década de 2000 afectaron a la estructura de los vencimientos de los pasivos del banco en el extranjero.

Si bien las medidas financieras prudenciales han sido el principal instrumento normativo elegido por los encargados de la formulación de políticas coreanos, la República de Corea también ha adoptado controles de

\footnotetext{
7 Según Pradhan y otros (2011), la disminución de la demanda de contratos de compra de moneda a término (sobre todo de los constructores navales, debido a una menor cartera de pedidos en el período posterior a la crisis) también ha contribuido a poner coto a la apreciación del tipo de cambio nominal entre el won y el dólar.
}

capital para paliar los efectos indeseados de los flujos de capital. En tal sentido, la principal medida de control de capital consistió en la retención de impuestos en la fuente sobre la tenencia por extranjeros de bonos del Estado y valores del Banco Central, de modo que ese gravamen volvió a ponerse en consonancia con el impuesto aplicado a los bonos adquiridos por los residentes. Este control de capital basado en los precios volvió a imponerse en enero de 2011 debido al gran aumento de las entradas de cartera de deuda, que alcanzaron niveles sin precedentes (FMI, 2011a). Sin embargo, el efecto de esa medida en las entradas de inversiones de cartera probablemente será marginal, por dos motivos. En primer lugar, se aplica una exención a las empresas extranjeras y los inversores no residentes procedentes de países que tienen tratados con la República de Corea para evitar la doble tributación, y la República de Corea tiene tratados de ese tipo con más de 70 países. En segundo lugar, ese impuesto no afecta a las corrientes de inversiones de cartera, que también han aumentado de forma significativa desde 2009 (Pradhan y otros, 2011).

\section{Brasil}

El Gobierno del Brasil respondió a la crisis cambiara de 1999 con la adopción de un nuevo conjunto de políticas económicas basadas en una meta de inflación y un tipo de cambio gestionado (o de flotación sucia). Ese cambio del régimen macroeconómico estuvo acompañado de un proceso de apertura financiera que comenzó en 1990 y cobró impulso en enero de 2000, cuando en virtud de la Resolución No 2689 del Conselho Monetário Nacional (CMN) se concedió acceso sin restricciones a los inversores no residentes (o sea, extranjeros) a todos los segmentos del mercado financiero nacional, incluido el mercado de derivados. Además, en 2005 se liberalizaron por completo las exportaciones de capital por los residentes. De ese modo, la economía del Brasil se abrió del todo a las entradas y salidas de capital.

En ese contexto de alta movilidad del capital, la situación posterior a la crisis mundial — combinada con los factores internos (sobre todo la reanudación del crecimiento económico y las tasas de interés muy elevadas, según las normas internacionales, hasta hace poco tiempo) - trajo grandes entradas de capital e importantes presiones a la apreciación entre 2009 y mediados de 2011 (véanse el gráfico 2 y el cuadro 3$)^{8}$. Dos características específicas de la economía del Brasil (en

${ }^{8}$ El Brasil pasó a ser el destino principal de los flujos de capital en América Latina en ese período (FMI, 2011a). 
GRÁFICO 2

Brasil: diferencial de la tasa de interés y tipo de cambio nominala (En porcentajes y reales por dólar)
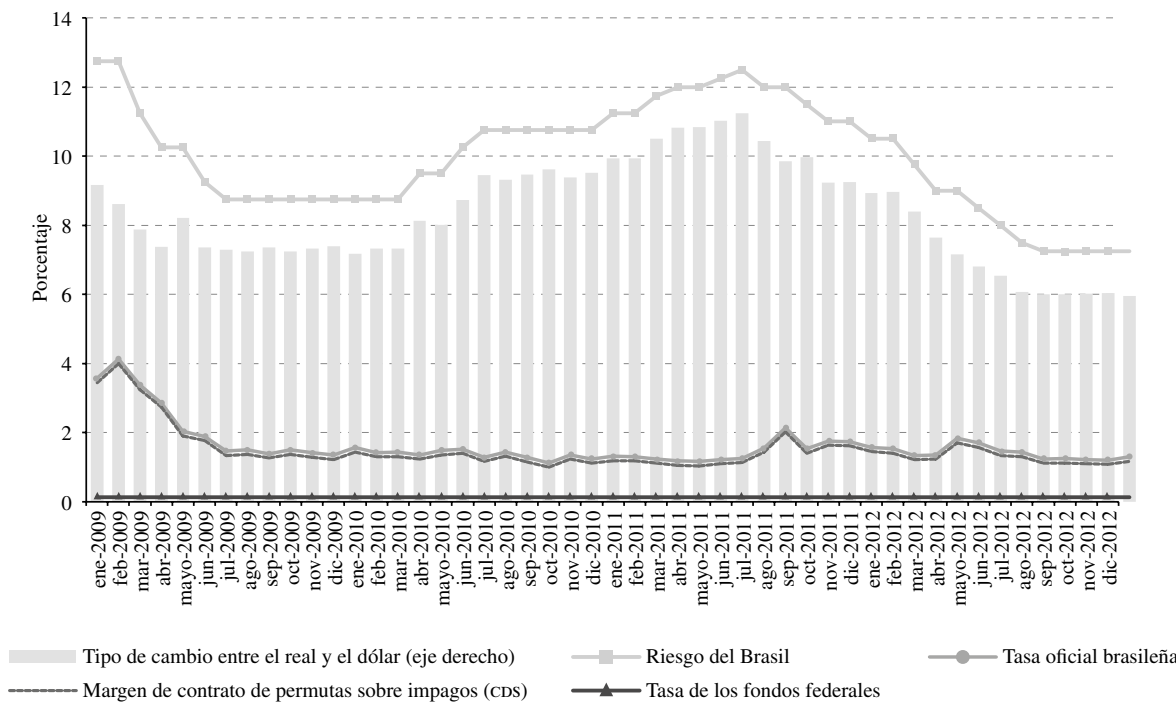

Fuente: Elaboración propia sobre la base de información del Banco Central del Brasil.

${ }^{a}$ La tasa oficial brasileña más el riesgo del Brasil menos la tasa de los fondos federales.

CUADRO 3

Brasil y República de Corea: selección de datos macroeconómicos

\begin{tabular}{|c|c|c|c|c|c|c|c|c|}
\hline \multirow{2}{*}{ Año } & \multicolumn{2}{|c|}{$\begin{array}{l}\text { Tasa oficial de interés } \\
\quad \text { (en porcentajes) }\end{array}$} & \multicolumn{2}{|c|}{$\begin{array}{c}\text { Reservas de divisas } \\
\text { (en miles de millones de dólares) }\end{array}$} & \multicolumn{2}{|c|}{$\begin{array}{c}\text { Inflación } \\
\text { (en porcentajes) }\end{array}$} & \multicolumn{2}{|c|}{$\begin{array}{l}\text { Resultado fiscal (nominal y } \\
\text { en porcentajes del } P N B \text { ) }\end{array}$} \\
\hline & Brasil & $\begin{array}{l}\text { República } \\
\text { de Corea }\end{array}$ & Brasil & $\begin{array}{l}\text { República } \\
\text { de Corea }\end{array}$ & Brasil & $\begin{array}{l}\text { República } \\
\text { de Corea }\end{array}$ & Brasil & $\begin{array}{l}\text { República } \\
\text { de Corea }\end{array}$ \\
\hline 2003 & 23,55 & 3,96 & 48844 & 154509 & 17,05 & 3,5 & $-5,23$ & 0,47 \\
\hline 2004 & 16,38 & 3,6 & 52458 & 198175 & 6,29 & 3,6 & $-2,9$ & 2,72 \\
\hline 2005 & 19,14 & 3,33 & 53216 & 209968 & 5,77 & 2,8 & $-3,58$ & 3,38 \\
\hline 2006 & 15,32 & 4,23 & 85148 & 238388 & 3,27 & 2,2 & $-3,63$ & 3,92 \\
\hline 2007 & 12,05 & 4,73 & 179431 & 261771 & 4,08 & 2,5 & $-2,80$ & 4,65 \\
\hline 2008 & 12,44 & 4,73 & 192842 & 200479 & 6,57 & 4,7 & $-2,0$ & 2,96 \\
\hline 2009 & 10,16 & 2,04 & 231888 & 265202 & 5,06 & 2,8 & $-3,3$ & $-1,14$ \\
\hline 2010 & 9,89 & 2,17 & 280570 & 286926 & 5,11 & 2,9 & $-2,5$ & $-0,04$ \\
\hline 2011 & 11,76 & 3,1 & 343384 & 298233 & 6,6 & 4,0 & n.d. & n.d. \\
\hline
\end{tabular}

Fuente: Elaboración propia sobre la base de Oxford Economics [en línea] http://www.oxfordeconomics.com/; Fondo Monetario Internacional (FMI), Estadísticas Financieras Internacionales, e información estadística de los respectivos países.

relación con factores macroeconómicos e institucionales) hacían más acuciantes los dilemas de política económica que afrontaban las autoridades monetarias brasileñas en materia de gestión macroeconómica y regulación financiera en el contexto posterior a la crisis.

En lo que respecta al factor macroeconómico, la estrategia de acumulación de reservas del Brasil tropieza con dos dificultades importantes: un volumen significativo de deuda pública concentrada en vencimientos a corto plazo y una gran diferencia entre las tasas de interés internas y externas (ocasionada por la elevada tasa de interés oficial interna $)^{9}$. Esas limitaciones hicieron

\footnotetext{
${ }^{9}$ Este factor no es el tema principal del documento y, por lo tanto, no se describe aquí con detalle.
} 
que el costo de las operaciones de esterilización fuera excesivamente elevado, con lo que se redujo el margen normativo del Banco Central para la gestión de los tipos de cambio (Prates, Cunha y Lélis, 2009a).

Por lo que se refiere al factor institucional, que es el tema principal de este documento, tanto antes como después de la crisis financiera mundial, el mercado de derivados en moneda extranjera ha desempeñado un papel fundamental en el devenir de la moneda brasileña, el real, que ha seguido predominantemente una tendencia a la apreciación ${ }^{10}$. Esto ha menoscabado la capacidad de la autoridad monetaria de influir en el tipo de cambio (mediante intervenciones convencionales sobre los tipos de cambio, como por ejemplo, la intervención en el mercado de divisas al contado) y la eficacia de los controles de capital y las regulaciones financieras prudenciales para poner freno a la apreciación de la moneda.

Ese papel decisivo del mercado de derivados en moneda extranjera proviene del número mucho mayor de transacciones y el gran aumento del volumen financiero del mercado de futuros en moneda extranjera en comparación con el mercado de divisas al contado, que, a su vez, hace que el mercado de futuros en divisas tenga un mayor grado de desarrollo y liquidez que el mercado al contado. En ese entorno, las operaciones con futuros en divisas tienen una influencia fundamental en la tendencia del tipo de cambio entre el real y el dólar, como se señala en muchos estudios (Farhi, 2010; Ventura y García, 2009; Prates, Cunha y Lélis 2009a; Kaltenbrunner, 2010; Chamon y Garcia, 2013). El factor determinante más importante del mayor grado de liquidez y desarrollo del mercado de futuros en divisas en comparación con el mercado al contado es la prohibición de mantener cuentas (depósitos bancarios) en moneda extranjera, con escasas excepciones ${ }^{11}$. En otras palabras, si se sigue el concepto de apertura financiera propuesto por Akyüz (1993), la convertibilidad interna del real es muy limitada, pues casi todas las transacciones se liquidan en la moneda nacional. Por otra parte, la moneda brasileña tiene una

${ }^{10}$ El real brasileño fue la segunda moneda más comprada y vendida a nivel mundial en los mercados de derivados organizados en 2010, mientras que el volumen financiero de derivados en moneda extranjera comprados y vendidos en los mercados extrabursátiles sujetos a la reglamentación nacional fue bajo (18.000 millones de dólares en abril de 2010) en relación con otros mercados emergentes, como la República de Corea (Avdjiev, Upper y Vause, 2010).

11 Según el capítulo 14 del Regulamento do Mercado de Câmbio e Capitais Internacionais (Reglamento del mercado de divisas y capitales internacionales) (вСв, 2013), las cuentas bancarias denominadas en moneda extranjera solo están permitidas en el caso de las embajadas, las instituciones multilaterales y las empresas de seguros que tienen que ver con el comercio exterior. Aun así, su utilización es muy limitada. plena convertibilidad externa, pues las entradas y salidas de capital se han liberalizado por completo desde 2005.

Esa característica distintiva de la moneda brasileña se asocia con la elevada inflación de la década de 1980 y la primera mitad de los años noventa, que se caracterizaba por la indización generalizada, sobre todo en el sector financiero. La indización impedía la dolarización de las operaciones financieras internas y la desintermediación del proceso bancario. En consecuencia, este sector realizó sofisticadas operaciones de compraventa. La sofisticación financiera se vio facilitada, además, por el predominio de grandes bancos nacionales y extranjeros. Otro rasgo institucional del sistema financiero brasileño, vinculado también con la naturaleza particular del proceso inflacionario del país, es la existencia de un mercado desarrollado de derivados desde la década de 1980 (a saber, el BM\&F), donde se compran y venden los contratos de futuros en divisas ${ }^{12}$.

La convertibilidad interna limitada del real es el principal factor determinante de las características que distinguen a los mercados de divisas al contado y de derivados en moneda extranjera de los de la República de Corea, y de otras economías emergentes de América Latina, como México, Chile y Colombia. En lo que se refiere al mercado de divisas al contado, los residentes y no residentes no pueden tener cuentas en moneda extranjera, ni mantener posiciones en divisas al contado. En consecuencia, la mayoría de esas transacciones se liquidan mediante transferencias de fondos entre cuentas en divisa mantenidas en el extranjero ${ }^{13}$. Por lo tanto, no generan corrientes de divisas, sino que tienen su efecto en las posiciones de activos y pasivos en el extranjero de los no residentes y los residentes. Además, todas las transacciones en moneda extranjera tienen que registrarse en el marco de un contrato especial. Solo unos pocos bancos que el Banco Central del Brasil ha autorizado a tener carteras en divisas pueden mantener posiciones en divisas al contado, pues tienen acceso a líneas de crédito externas a corto plazo en el mercado interbancario internacional (denominadas "líneas limpias"). Sin embargo, los cambios de esas líneas de crédito no se registran con arreglo a un contrato en moneda extranjera porque solo afectan a los activos y pasivos de los bancos en el extranjero.

\footnotetext{
12 El 25 de marzo de 2008, el BM\&F se fusionó con BOVESPA, la principal bolsa de valores del Brasil.

${ }^{13}$ La excepción es la compraventa de moneda extranjera en relación con viajes internacionales. En ese caso, se permiten los flujos físicos (BCB, 2013).
} 
En lo que respecta al mercado de derivados en moneda extranjera (de futuros y extrabursátil), su naturaleza no ejecutable también se basa en la convertibilidad interna limitada del real. Es decir, las ganancias o pérdidas en ese mercado no se liquidan en la moneda extranjera, sino en la moneda nacional, que es lo que suele suceder en otros países. Precisamente por el hecho de que esas operaciones se liquidan en reales, cualquier agente puede mantener posiciones en el mercado de futuros en divisas mientras cumpla las normas mínimas exigidas por la Bolsa de Valores del Brasil (Ventura y García, 2009; Kaltenbrunner, 2010). En el caso de los contratos de futuros en divisas, los agentes principales son los bancos residentes (sean brasileños o de propiedad extranjera), inversores institucionales residentes, empresas residentes no financieras e inversores no residentes (que tienen acceso sin restricciones al mercado de derivados desde enero de 2000). Durante períodos de poca aversión al riesgo tanto antes de la crisis financiera mundial (de 2003 a mediados de 2008) como después de ella (principalmente, desde mediados de 2009 hasta mediados de 2011), esos inversores (sobre todo fondos de cobertura de riesgo) han sido el más importante grupo de inversores no bancarios en el mercado brasileño de futuros en divisas y han promovido una tendencia a la apreciación del real mediante operaciones de acarreo de derivados. Esto constituye un tipo de estrategia de especulación monetaria distinta de la modalidad canónica de operaciones de acarreo mediante operaciones en el mercado al contado (a saber, la obtención de empréstitos en divisas con bajas tasas de interés y la concesión de préstamos en divisas con altas tasas de interés (Burnside y otros, 2006; Gagnon y Chaboud, 2007; Kaltenbrunner, 2010)). En los mercados de derivados, la operación de acarreo se expresa como una apuesta que da lugar a posiciones cortas en la moneda de financiación y posiciones largas en la moneda objetivo (Gagnon y Chaboud, 2007).

Como ya se mencionó, el entorno macroeconómico brasileño se caracteriza por un régimen de flotación sucia adoptado en enero de 1999 y por uno de los diferenciales entre las tasas de interés más amplios de las economías emergentes (Prates, Cunha y Lélis, 2009a, véase el gráfico 2). Esto ha llevado a los inversores extranjeros a hacer apuestas unidireccionales sobre la apreciación de la moneda brasileña mediante posiciones cortas en el mercado de futuros en divisas, con la venta de dólares y la compra de reales ${ }^{14}$. El resultado es una presión a la

14 Es posible lucrar con la apreciación del real brasileño y el diferencial positivo de la tasa de interés mediante derivados sujetos a la reglamentación nacional que se venden en BM\&F-BOVESPA. Las baja sobre el precio del dólar y, por consiguiente, una presión al alza sobre el precio del real en el mercado de futuros (Farhi, 2010). Además, el impuesto sobre la renta aplicable a los rendimientos de los bonos del Estado en manos de inversores extranjeros, que estuvo en vigor hasta febrero de 2006, también hacía que resultaran más ventajosas las operaciones de acarreo de derivados en comparación con las operaciones de acarreo tradicionales.

Las operaciones de acarreo de derivados resultan ser aun más atractivas en el Brasil, debido a la característica no ejecutable del mercado de derivados en moneda extranjera. Los agentes extranjeros y nacionales pueden realizar operaciones de acarreo de derivados sin desembolsar ni un dólar. Hasta octubre de 2010, esa estrategia en las operaciones de acarreo también se podía ejecutar sin gastar un solo real, porque los inversores podían mantener sus depósitos de garantía mínimos en reales por medio de títulos o garantías nacionales tomados en préstamo de los bancos residentes. A pesar del predominio de los inversores extranjeros en las operaciones de acarreo de derivados, también han participado en este segmento del mercado financiero agentes nacionales con ánimo de lucro, como los inversores institucionales y las empresas.

Además, el extraordinario desempeño del mercado de futuros en reales ha contribuido al aumento de la compraventa de la moneda brasileña en los mercados extrabursátiles mediante contratos a término sin entrega. La existencia de un mercado de futuros desarrollado ha permitido que los bancos extranjeros con sucursales en el Brasil vendan reales extraterritorialmente $\mathrm{y}$, de forma simultánea, den cobertura a su exposición al real en el mercado de futuros sujeto a la reglamentación nacional (Kaltenbrunner, 2010). A su vez, el crecimiento del mercado de contratos a término sin entrega sobre el real brasileño ha hecho que aumente aún más el grado de liquidez y desarrollo del mercado de futuros brasileño. Por consiguiente, algunos inversores internacionales comenzaron a utilizar contratos de futuros en reales como sustituto indirecto de otros instrumentos derivados de monedas emergentes, que han mantenido una elevada correlación con el real brasileño, pero cuyos mercados de derivados no tienen gran desarrollo ni liquidez, como la lira turca y el rand sudafricano. Esa práctica hizo que aumentara aún más la compraventa de contratos de futuros en reales.

transacciones más comunes son la liquidación de posiciones cortas en contratos de futuros en dólares, la liquidación de posiciones cortas en contratos sobre el tipo aplicable al dólar sujeto a la reglamentación nacional, o la liquidación de posiciones cortas directamente sobre ese tipo de cambio, combinada con la actual posición larga sobre las tasas domésticas de interés de los futuros (DI x Pre) (Ventura y García, 2009). 
La amplia variedad de participantes garantiza un mayor número de transacciones y volumen financiero en el mercado de futuros en divisas en comparación con el mercado de divisas al contado. Como han señalado Ventura y García (2009), dada la mayor liquidez del mercado de futuros en divisas, los bancos que tienen carteras en divisas han optado por transferir operaciones típicas del mercado de divisas al contado al mercado de futuros en divisas, lo que ha hecho que aumenten sus transacciones con ese tipo de futuros. Como afirman esos autores, el primer contrato de futuros en dólares (con plazo de liquidación de 30 días) se ha convertido en el locus de formación del tipo de cambio entre el real y el dólar, partiendo de su elevada liquidez. El tipo de cambio al contado es resultado del arbitraje entre el tipo aplicable al mercado de futuros y el tipo de cambio al contado que aplican los bancos que tienen carteras en divisas. En general, esos agentes se encuentran en la situación contraria a la de los inversores no bancarios (entre los que se destacaron los inversores extranjeros desde 2009 hasta mediados de 2011) en el mercado de futuros en divisas: mantienen posiciones largas en dólares y posiciones cortas en reales, lo que significa que compran dólares en ese mercado y los venden en el mercado al contado. Con esa estrategia, los bancos han obtenido ganancias de arbitraje y, al mismo tiempo, generado presiones sobre el precio al contado del dólar, lo que ha hecho que disminuya el tipo de cambio al contado entre el real y el dólar y se aprecie la moneda brasileña. Dado que solo los bancos pueden mantener posiciones en moneda extranjera en el mercado de divisas al contado del Brasil, estos han desempeñado un papel fundamental al transmitir la presión a la apreciación mediante las operaciones de acarreo en el mercado de futuros al tipo de cambio al contado entre el real y el dólar ${ }^{15}$. Al mismo tiempo, ese papel clave de los futuros en divisas en la dinámica del tipo de cambio entre el real y el dólar no significa que las transacciones en divisas al contado no tengan también su influencia. El arbitraje cambiario entre estos dos instrumentos solamente funciona si hay liquidez en el mercado al contado, lo que depende de las entradas y salidas efectivas de moneda extranjera.

El objetivo principal de los controles de capital, las regulaciones financieras prudenciales y las regulaciones

\footnotetext{
15 Burnside y otros (2006), y Klitgaard (2004) han destacado el papel de los derivados en moneda extranjera en la actual dinámica cambiaria de las monedas de las economías avanzadas. Sin embargo, el análisis teórico de la influencia clave de esos instrumentos en la dinámica cambiaria dista mucho de estar consolidado.
}

sobre los derivados de divisas puestos en práctica en el Brasil desde octubre de 2009 es frenar la apreciación del real. El día después de anunciado el primer control, el Ministro de Hacienda, Guido Mantega, afirmó: "Deseamos evitar una apreciación excesiva del real. Cuando aumenta el valor del real, esto hace que las exportaciones se encarezcan y las importaciones se abaraten, y ya tenemos un importante aumento de las importaciones mientras que las exportaciones no han crecido como deberían" (citado en Chamon y Garcia, 2013, pág. 7). Guido Mantega anunció públicamente cada medida y en todas sus intervenciones sobre la aplicación de estas, se refirió repetidamente a los flujos de capital como un tsunami provocado por la política monetaria laxa de los Estados Unidos de América y otros países. Afirmó que el impuesto a las transacciones financieras (IOF) y otras medidas conexas eran la única defensa del Brasil frente a ese tsunami y la "guerra cambiaria" que le imponen los Estados Unidos de América y China (Gallagher, 2014).

De este modo, determinadas características del mercado monetario brasileño suponían para los encargados de la formulación de políticas del Brasil mayores dificultades que las que afrontaban sus homólogos coreanos. Por una parte, en vista de que los derivados en moneda extranjera no son ejecutables, pueden simular el impacto de los flujos de capital en el tipo de cambio sin que haya en efecto ninguna corriente de moneda extranjera, con lo que se reduce la eficacia de los controles de capital. Por otra, dado el predominio de los futuros en divisas, la regulación financiera prudencial también ha resultado insuficiente para alcanzar las operaciones con derivados en moneda extranjera, puesto que no abarca a los inversores no residentes y los agentes residentes no bancarios. No obstante, esa regulación sí afecta a las posiciones cortas en dólares de los bancos en el mercado de divisas al contado, que quedan fuera del alcance de los controles de capital que solo se aplican a las corrientes de moneda extranjera registradas en los contratos pertinentes.

Las autoridades normativas brasileñas reconocen esas limitaciones. Desde octubre de 2010, junto con los controles de capital y las regulaciones financieras prudenciales, han aplicado regulaciones sobre los derivados en moneda extranjera que se aplican a las operaciones correspondientes de todos los agentes, sean actores residentes o no, financieros o no.

En octubre de 2010, además de fortalecer un control de capital basado en los precios sobre la inversión de cartera (un gravamen sobre las entradas de capital denominado (IOF)), el Gobierno del Brasil puso en marcha la primera regulación sobre derivados de divisas: el IOF 
aplicable a los depósitos de garantía mínimos para las transacciones con derivados en moneda extranjera se aumentó del 0,38\% al 6,0\%, y se eliminaron algunos resquicios para evadir ese impuesto (véase el cuadro 4). Sin embargo, está claro que las primeras rondas de controles de capital y regulaciones sobre derivados en moneda extranjera no han detenido la apreciación de la moneda. Los agentes privados encontraron resquicios para eludir

CUADRO 4

Brasil: conjunto de instrumentos de regulación financiera

\begin{tabular}{|c|c|c|c|}
\hline Fecha & Número y tipo & Más o menos estrictas & Medida \\
\hline Octubre de 2009 & Primer CC & Más estrictas & $\begin{array}{l}\text { - El Ministerio de Hacienda implementó un impuesto del } 2 \% \\
\text { sobre las transacciones financieras (IOF) sobre las entradas de } \\
\text { inversiones de cartera y de renta fija de los no residentes. }\end{array}$ \\
\hline Octubre de 2010 & Segundo CC & Más estrictas & $\begin{array}{l}\text { - Se aumentó el IOF de un } 2 \% \text { a un } 4 \% \text { en el caso de las entradas } \\
\text { de renta fija y los fondos de capital. } \\
\text { - Se aumentó el IOF a un } 6 \% \text { en el caso de las inversiones de } \\
\text { renta fija. } \\
\text { - También se introdujeron límites a la capacidad de los inversores } \\
\text { extranjeros de cambiar de inversiones de cartera a inversiones de }\end{array}$ \\
\hline
\end{tabular}
renta fija.

Octubre de $2010 \quad$ Primera FXDR Más estrictas

- El IOF sobre los depósitos de garantía mínimos aplicable a las transacciones con derivados en divisas aumentó del $0,38 \%$ al $6 \%$.

- Se eliminaron los resquicios del IOF sobre los depósitos de garantía mínimos: se prohibió que los inversores extranjeros en el mercado de futuros hicieran sus depósitos de garantía mínimos mediante empréstitos locales de títulos o garantías de bancos locales, lo que les permitía eludir el pago del impuesto.

Enero de $2011 \quad$ Primera PR Más estrictas

- Requisito de reserva sin intereses equivalente al $60 \%$ de las posiciones cortas de los bancos en dólares en el mercado de divisas al contado que superaran los 3000 millones de dólares o su base de capital; la cantidad que sea menor de las dos (que se aplicaría en un plazo de 90 días).

Marzo de $2011 \quad$ Tercer cC $\quad$ Más estrictas

- El IOF sobre nuevos préstamos extranjeros (préstamos bancarios y valores emitidos en el extranjero) con plazos de vencimiento de hasta un año se aumentó al 6\%. Anteriormente, las empresas y bancos solo pagaban un impuesto del $5,38 \%$ sobre préstamos de hasta 90 días.

\begin{tabular}{|c|c|c|c|}
\hline Abril de 2011 & Cuarto CC & Más estrictas & $\begin{array}{l}\text { - Se extendió el IOF del } 6 \% \text { sobre la prórroga de préstamos } \\
\text { extranjeros con plazos de vencimiento de hasta un año. } \\
\text { - Se extendió el IOF del } 6 \% \text { aplicable a los préstamos extranjeros } \\
\text { tanto nuevos como prorrogados, con plazos de vencimiento de } \\
\text { hasta dos años. }\end{array}$ \\
\hline Julio de 2011 & Segunda PR & Más estrictas & $\begin{array}{l}\text { El requisito de reserva sin intereses pasó a ser de cumplimiento } \\
\text { obligatorio en el caso de montos superiores a los } 1000 \text { millones } \\
\text { de dólares o su base de capital (la cantidad que sea menor de } \\
\text { las dos). }\end{array}$ \\
\hline Julio de 2011 & Segunda FXDR & Más estrictas & $\begin{array}{l}\text { - Se aplica un impuesto financiero del } 1 \% \text { a las posiciones largas } \\
\text { excesivas sobre el real brasileño de todos los agentes; ese } \\
\text { impuesto se puede aumentar hasta el } 25 \% \text {. }\end{array}$ \\
\hline Diciembre de 2011 & Quinto CC & Menos estrictas & $\begin{array}{l}\text { - Se redujo al } 0 \% \text { el IOF sobre las entradas de inversiones de cartera } \\
\text { y de renta fija (vinculadas con proyectos de infraestructura). }\end{array}$ \\
\hline
\end{tabular}


Cuadro 4 (conclusión)

\begin{tabular}{|c|c|c|c|}
\hline Fecha & Número y tipo & Más o menos estrictas & Medida \\
\hline Marzo de 2012 & Tercera FXDR & Menos estrictas & $\begin{array}{l}\text { Los exportadores realizan operaciones de cobertura sobre las } \\
\text { operaciones (hasta 1,2 veces las exportaciones del año anterior) } \\
\text { exentas del IOF. }\end{array}$ \\
\hline Junio de 2012 & Séptimo CC & Menos estrictas & $\begin{array}{l}\text { IOF del } 6 \% \text { solo sobre los préstamos nuevos y prorrogados con } \\
\text { plazos de vencimiento de hasta dos años (o sea, se revirtieron los } \\
\text { cambios adoptados en marzo). }\end{array}$ \\
\hline Diciembre de 2012 & Octavo cc & Menos estrictas & $\begin{array}{l}\text { - IOF del } 6 \% \text { solo sobre los préstamos nuevos y prorrogados con } \\
\text { plazos de vencimiento de hasta un año. } \\
\text { - Se prorrogó el plazo de vencimiento de las transacciones de } \\
\text { pagos por anticipado de exportaciones de uno a cinco años. }\end{array}$ \\
\hline
\end{tabular}

Fuente: Elaboración propia sobre la base de información del Banco Central del Brasil [en línea] http://www.bcb.gov.br/pt-br/paginas/default. aspx; y del Ministerio de Hacienda [en línea] http://www.fazenda.gov.br/.

Nota: CC: Control de capital; PR: Regulación prudencial; FXDR: Regulación sobre los derivados de divisas; IOF: Impuesto a las transacciones financieras.

esos controles, y las regulaciones sobre los derivados en moneda extranjera no fueron suficientes para poner coto a las operaciones de acarreo de derivados, debido al alto grado de apalancamiento de estas últimas (véase el gráfico 3). De hecho, el IOF aplicable a las entradas de cartera de deuda solamente promovió la acumulación de posiciones largas o cortas en dólares en el mercado de derivados sujeto a la reglamentación nacional; es decir, estimuló las operaciones de acarreo de derivados facilitadas por los bancos residentes que tienen carteras en divisas y que asumían la posición contraria a la de los inversores no residentes en el mercado de derivados (posiciones largas o cortas en dólares). En vista de que esos bancos tienen que acatar las medidas prudenciales referentes a sus posiciones en divisas, acrecentaron sus posiciones cortas en dólares en el mercado de divisas al contado con el objetivo de reducir o eliminar el riesgo cambiario (FMI, 2011a).

GRÁFICO 3

Brasil: tipo de cambio nominal y aplicación de regulaciones más estrictas (En reales por dólar)

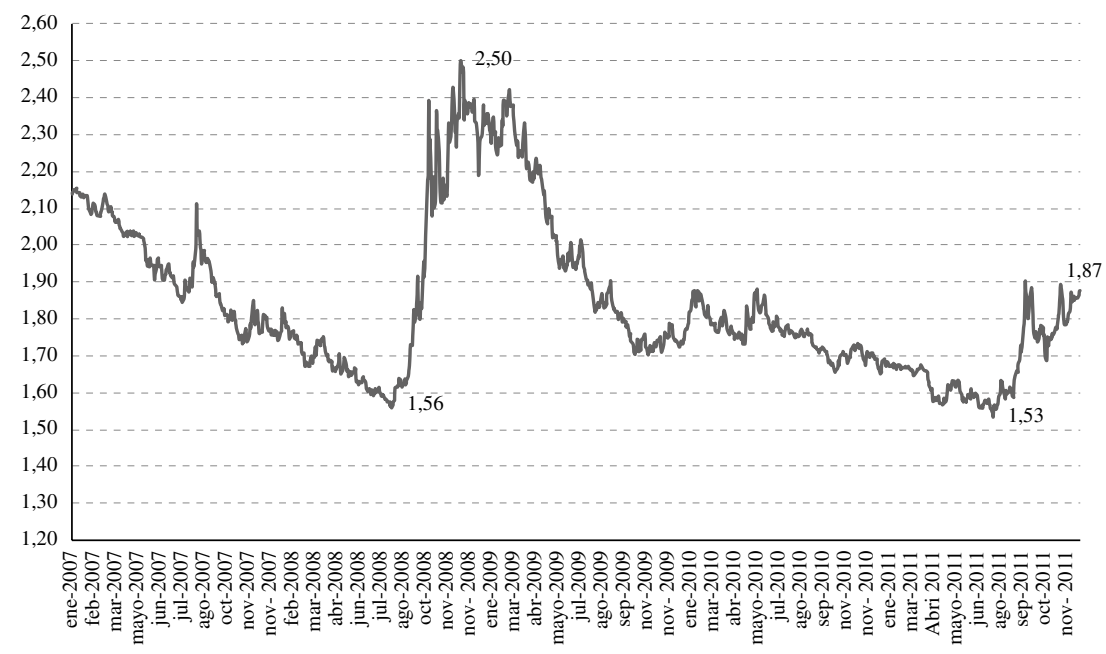

Fuente: Elaboración propia sobre la base de información del Banco Central del Brasil. 
Con el fin de eliminar ese resquicio, en enero de 2010, el Banco Central del Brasil impuso un requisito de reserva sin intereses (una regulación financiera prudencial) sobre esas posiciones. No obstante, al cambiar al endeudamiento externo a corto plazo, los bancos y empresas encontraron otra vía de eludir las regulaciones. En respuesta, el gobierno impuso el IOF al endeudamiento externo a corto plazo en marzo de 2011, pero los agentes privados podían realizar préstamos a más largo plazo, dados el exceso de liquidez y la búsqueda de rendimiento en el mercado financiero internacional. En abril de 2011, el gobierno también extendió el IOF a esos préstamos.

La moneda siguió apreciándose (véase el gráfico 3). En julio de 2011, el Gobierno reforzó la regulación financiera prudencial adoptada en enero y puso en marcha un conjunto más amplio de regulaciones sobre derivados en moneda extranjera, con inclusión de un impuesto financiero del $1 \%$ sobre posiciones excesivamente largas en reales en el mercado de derivados en moneda extranjera. Debido a que ese impuesto se calcula sobre el valor hipotético de las operaciones con derivados, tuvo un gran efecto en las operaciones de acarreo de derivados y era comparable con el IOF aplicable al depósito de garantía mínimo que ya estaba en vigor. La adopción de ese impuesto fue posible porque, al mismo tiempo, se encomendó al CMN la responsabilidad de regular el mercado de derivados y se adoptaron nuevas reglas acerca del registro de derivados en moneda extranjera. El CMN está compuesto por el Presidente del Banco Central, el Ministro de Hacienda y el Ministro de Planificación, Presupuesto y Gestión (véase [en línea] www.bcb.gov. $\mathrm{br} /$ ?CMN). De ese modo, esas instituciones podían coordinar fácilmente sus iniciativas encaminadas a contener las presiones a la apreciación que tienen su origen en ese segmento del mercado.

Esas medidas surtieron algún efecto, al menos a corto plazo. No obstante, poco tiempo después tuvieron lugar cambios importantes en el entorno externo y en la política monetaria nacional que también influyeron en el devenir del tipo de cambio. En primer lugar, la aversión al riesgo de los agentes extranjeros, medida según el índice de volatilidad VIX, creció en medio del empeoramiento de la crisis del euro (véase el gráfico 4). En segundo lugar, el cambio normativo iba incorporado en una importante reducción de la tasa oficial a partir de agosto de 2011 (véase el gráfico 2). Sin embargo, aunque el viX comenzó a aumentar en la primera semana de julio, la moneda brasileña solo empezó a depreciarse después de la puesta en marcha de las nuevas regulaciones sobre derivados en moneda extranjera, pero antes de las reducciones de la tasa oficial en agosto (véanse los gráficos 2,3 y 4).

GRÁFICO 4

Índice de volatilidad VIX

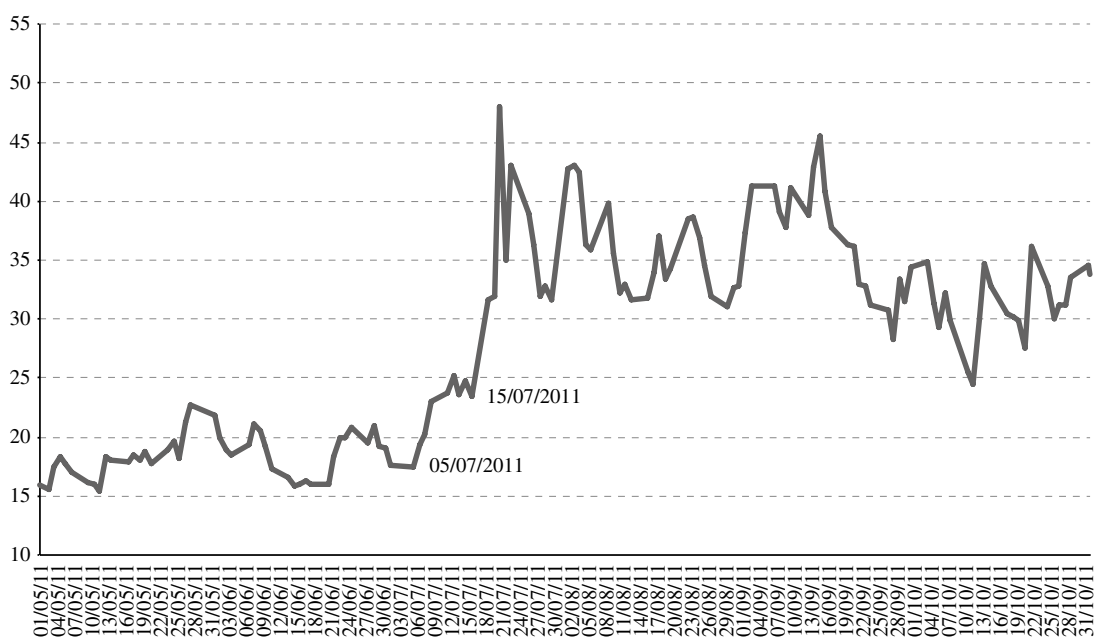

Fuente: Elaboración propia sobre la base de información del Chicago Board Options Exchange. 
En algunos estudios empíricos se da a entender que, con el conjunto de instrumentos normativos del Brasil, se logró el efecto deseado de frenar la tendencia a la apreciación de la moneda. Por ejemplo, Chamon y Garcia (2013) subrayan la posibilidad de que las medidas adoptadas con miras a frenar la apreciación de la moneda hayan amplificado los efectos de la reducción de la tasa oficial entre agosto de 2011 y octubre de 2012 sobre el tipo de cambio entre el real y el dólar. Baumann y Gallagher (2012) concluyen que la regulación establecida por los encargados de la formulación de políticas brasileños entre octubre de 2009 y diciembre de 2012, que se vinculaba a una transición de entradas de corto plazo a otras entradas de más largo plazo, tuvo un efecto duradero en el nivel y la volatilidad del tipo de cambio e hizo que se acrecentara ligeramente la autonomía de la política monetaria del Brasil. Por otra parte, Klein (2012) señala que el IOF brasileño fue un control episódico sobre las entradas de capital que no moderaba la apreciación de la moneda brasileña; no obstante, debe tenerse en cuenta que el período que abarca su estudio finaliza en 2010, antes de la adopción de regulaciones más amplias sobre derivados en moneda extranjera.

GRÁFICO 5

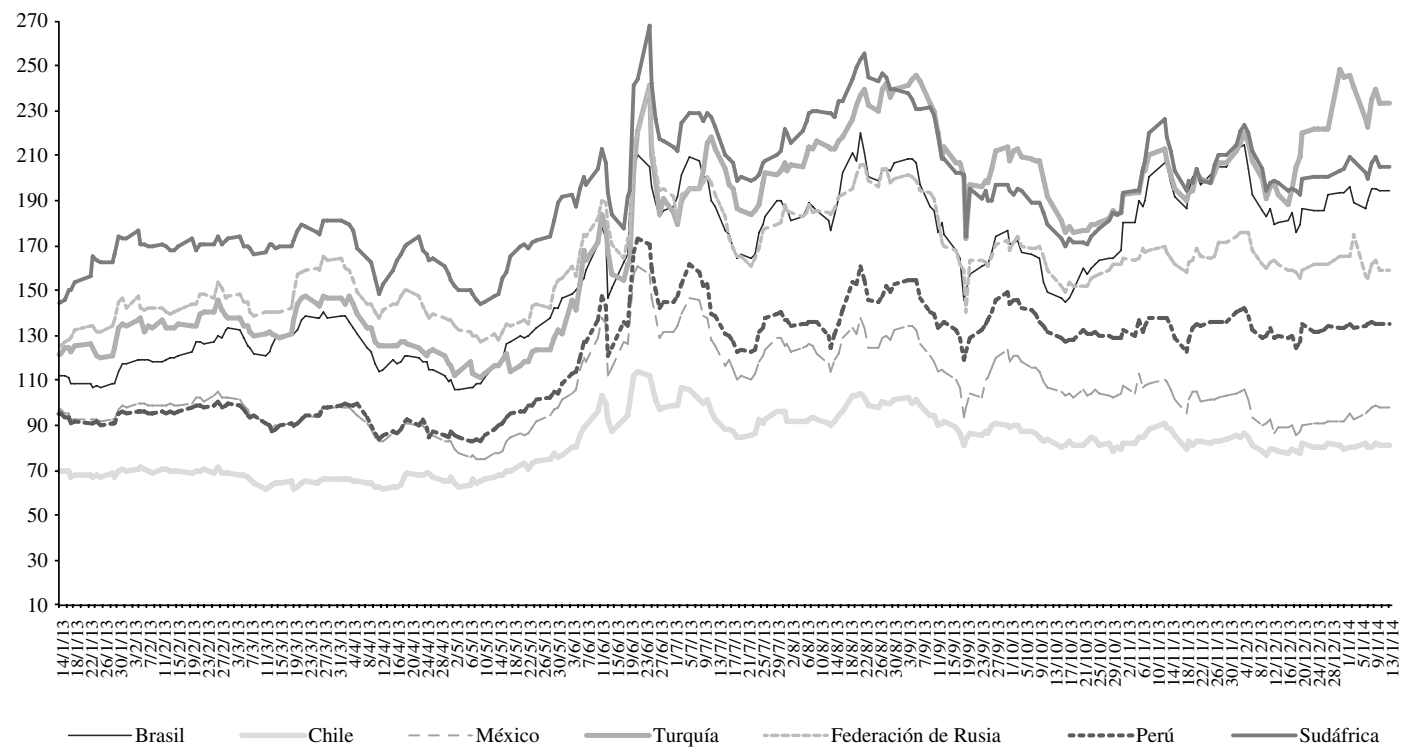

Fuente: Elaboración propia sobre la base de información de Bloomberg.

Nota: CDS: Margen de contrato de permutas sobre impagos.

\section{IV}

\section{Conclusiones}

Al tratarse de países emergentes con cuentas financieras abiertas y mercados sofisticados de derivados en moneda extranjera, los estudios de caso del Brasil y la República de Corea constituyen un ejemplo de la necesidad de considerar los factores específicos de cada país en el diseño del conjunto de instrumentos de regulación financiera destinados a frenar las estrategias especulativas de los agentes extranjeros y nacionales en búsqueda de rendimiento. De este análisis comparativo pueden extraerse tres conclusiones.

En primer lugar, la necesaria amplitud de la regulación financiera depende de los agentes financieros involucrados y del tipo de contrato financiero. En el Brasil, fue necesario aplicar un tercer tipo de normativa, que 
aquí se denomina regulación de los derivados en moneda extranjera, porque el lugar principal donde ocurren las operaciones en dicha moneda es el mercado organizado de derivados, donde participan bancos y agentes financieros no bancarios residentes y no residentes. Por consiguiente, la regulación financiera prudencial no es suficiente. El caso del Brasil también puede utilizarse como ejemplo de que los controles de capital son insuficientes para poner freno a los derivados en moneda extranjera, porque tanto las operaciones de residentes como las de no residentes se denominan en moneda extranjera, pero se liquidan en la moneda nacional, y el efecto en el tipo de cambio de las decisiones de cartera de los inversores extranjeros puede desvincularse del volumen de flujos internacionales de capital. A su vez, en la República de Corea, la regulación financiera prudencial ha sido capaz de influir en las operaciones con derivados en moneda extranjera, porque estas se llevan a cabo sobre todo en los mercados extrabursátiles — donde los bancos cumplen la función de contraparte en todas las transacciones-y las operaciones se liquidan en dólares. De ese modo, la regulación prudencial puede abarcar todas las operaciones.

En segundo lugar, las especificaciones institucionales en sentido estricto son pertinentes. Es relevante contar con instituciones nacionales eficaces y jurisdicciones capaces de formular y aplicar regulaciones. A diferencia de muchas economías emergentes, el Brasil posee un marco institucional que da a las autoridades financieras la discrecionalidad necesaria para intervenir rápidamente e imponer regulaciones sobre los flujos de capital y los derivados en moneda extranjera. El marco se basa en tres instrumentos institucionales: i) las normas nacionales sobre las transacciones en moneda extranjera permiten aplicar controles de capital y regulaciones sobre los derivados en moneda extranjera en cualquier momento; ii) el Ministerio de Hacienda del Brasil tiene jurisdicción sobre toda la política tributaria, incluido cualquier gravamen aplicable a las finanzas transfronterizas, y iii) todas las políticas monetarias, crediticias y cambiarias del Brasil tienen que decidirse de manera consensuada a través del CMN, órgano que incluye representantes del Banco Central y del Ministerio de Hacienda. De ese modo, es posible coordinar adecuadamente las políticas monetarias y cambiarias y la regulación financiera, lo que parece ser muy pertinente para determinar su eficacia potencial (Prates y Fritz, 2014).

En tercer lugar, los países no deberían limitar su propio margen normativo mediante acuerdos multilaterales o bilaterales; más bien tales acuerdos deberían dejar un margen de maniobra para las políticas nacionales. El Brasil ha conseguido poner en marcha amplios controles de capital y regulaciones sobre los derivados en moneda extranjera porque, desde la década de 1990, el gobierno ha puesto cuidado en no asumir ningún compromiso en el marco del Acuerdo General sobre el Comercio de Servicios (AGCS), ni firmar tratados bilaterales sobre inversiones ni acuerdos de libre comercio que pudieran reducir el margen normativo del país para aplicar esas regulaciones en cualquier momento (Paula y Prates, 2013). Si bien en la mayoría de los tratados en que se liberaliza el comercio de servicios se emplea un enfoque de "lista positiva" con respecto al comercio de servicios financieros, los controles de capital y las regulaciones sobre los instrumentos en moneda extranjera podrían resultar incompatibles con las obligaciones emanadas de los tratados si intervienen en los movimientos transfronterizos del capital relacionado con dichos servicios. La República de Corea, en su calidad de Estado miembro de la OCDE, tiene muchas más restricciones en cuanto a la regulación de las transacciones financieras transnacionales, y también ha suscrito tratados sobre doble tributación con la mayoría de los países que son socios económicos, de modo que no se aplican impuestos a los flujos de capital. Por consiguiente, la presencia dominante de los bancos residentes en las transacciones internacionales de flujos de capital fue lo que permitió que las autoridades coreanas regularan las operaciones pertinentes.

\section{Bibliografía}

Akyüz, Y. (2011), "Capital flows to developing countries in a historical perspective. Will the current boom end with a bust and how?", Research Paper, $\mathrm{N}^{\circ} 37$, Centro del Sur.

(1993), "Financial liberalization: the key issues", UNCTAD Discussion Papers, $\mathrm{N}^{\circ} 56$, Ginebra, Conferencia de las Naciones Unidas sobre Comercio y Desarrollo (UNCTAD).

Ariyoshi, A. y otros (2000), "Capital controls. Country experiences with their use and liberalization", IMF Occasional Papers, $\mathrm{N}^{\circ}$ 190, Washington, D.C., Fondo Monetario Internacional.

Avdjiev, S., Ch. Upper y N. Vause (2010), "Highlights of international banking and financial market activity", BIS Quarterly Review, Basilea, Banco de Pagos Internacionales, diciembre.
Baba, Ch. y A. Kokenyne (2011), "Effectiveness of capital controls in selected emerging markets in the 2000s", IMF Working Paper, $\mathrm{N}^{\circ}$ WP/11/281, Washington, D.C., Fondo Monetario Internacional.

Banco Mundial (2001), Financiamiento para el crecimiento económico. Opciones de política en un mundo volátil, Washington, D.C., Alfaomega.

Baumann, B.A. y K.P. Gallagher (2013), "Post-crisis capital account regulation in South Korea and South Africa", PERI Working Paper, $\mathrm{N}^{\circ}$ 320, Amherst, Political Economy Research Institute. (2012), "Navigating capital flows in Brazil and Chile", Initiative for Policy Dialogue Working Paper Series [en línea] 
http://policydialogue.org/files/publications/Working_PaperNavigating_Capital_Flows_in_Brazil_and_Chile.pdf.

всв (Banco Central del Brasil) (2013), "International Capital and Foreign Exchange Market Regulation-RMCCI" [en línea] http:// www.bcb.gov.br/?RMCCINORMS

Bhagwati, J. (1998), "Why Free Capital Mobility May be Hazardous to Your Health: Lessons from the Latest Financial Crisis" [en línea] http://academiccommons.columbia.edu/catalog/ ac\%3A123599.

Blanchard, O., G. Dell'Ariccia y P. Mauro (2010), "Rethinking macroeconomic policy", IMF Staff Position Note, $\mathrm{N}^{\circ} \mathrm{SPN} / 10 / 03$, Washington, D.C., Fondo Monetario Internacional.

BPI (Banco de Pagos Internacionales) (2010), Triennial Central Bank Survey. Report on Global Foreign Exchange Market Activity in 2010, Basilea [en línea] http://www.bis.org/publ/rpfxf10t.pdf

Bruno, V. y H.S. Shin (2013), "Assessing macroprudential policies: case of Korea", NBER Working Paper, $\mathrm{N}^{\circ} 19084$, Cambridge, Massachusetts, National Bureau of Economic Research.

Burnside, C. y otros (2006), "The returns to currency speculation", NBER Working Paper, $\mathrm{N}^{\circ} 12489$, Cambridge, Massachusetts, National Bureau of Economic Research.

Canuto, O. y M. Giugale (eds.) (2010), The Day After Tomorrow. A Handbook on the Future of Economic Policy in the Developing World, Washington, D.C., Banco Mundial.

Canuto, O. y D. Leipziger (eds.) (2012), Ascent after Decline: Regrowing Global Economies after the Great Recession, Washington, D.C., Banco Mundial.

Chamon, M. y M. Garcia (2013), "Capital controls in Brazil: effective?" [en línea] https://www.imf.org/external/np/res/ seminars/2014/arc/pdf/chamon_garcia.pdf.

Cordero, J. y J.A. Montecino (2010), Capital Controls and Monetary Policy in Developing Countries, Washington, D.C., Centro de Investigación sobre Políticas Económicas.

Dell'Ariccia, G. y otros (2008), "Reaping the benefits of financial globalization", IMF Occasional Paper, $\mathrm{N}^{\circ}$ 264, Washington, D.C., Fondo Monetario Internacional.

Dodd, R. (2009), "Exotic derivatives losses in emerging markets: questions of suitability, concerns for stability", IMF Working Paper, $\mathrm{N}^{\circ}$ WP/09, Washington, D.C., Fondo Monetario Internacional.

Dooley, M. (1996), "A survey of literature on controls over international capital transactions", IMF Staff Papers, vol. 43, $\mathrm{N}^{\circ}$ 4, Washington, D.C., Palgrave Macmillan.

Eichengreen, B. y otros (2011), Rethinking Central Banking. Committee on International Economic Policy and Reform, Washington, D.C., Brookings.

Epstein, G., I. Grabel y K.S. Jomo (2004), "Capital management techniques in developing countries: an assessment of experiences from the 1990s and lessons for the future", $G-24$ Discussion Paper, $\mathrm{N}^{\circ} 27$, Ginebra, Conferencia de las Naciones Unidas sobre Comercio y Desarrollo.

Farhi, M. (2010), "Os impactos dos derivativos no Brasil", Sistema financeiro e desenvolvimento no Brasil, L.C. Marcolino y R. Carneiro (eds.), São Paulo, Atitude.

Farhi, E. e I. Werning (2012), "Dealing with the trilemma: optimal capital controls with fixed exchange rates", NBER Working Paper, $\mathrm{N}^{\circ} 18199$, Cambridge, Massachusetts, National Bureau of Economic Research.

Fettig, D. (1996), "Interview with James Tobin", The Region, Banco de la Reserva Federal de Minneapolis, 1 de diciembre [en línea] http://bit.ly/VpqsgL.

FMI (Fondo Monetario Internacional) (2012a), "Liberalizing capital flows and managing capital outflows", Public Information Notice, $\mathrm{N}^{\circ}$ 12/42 [en línea] http://bit.ly/SLs06q

(2012b), "The Liberalization and Management of Capital Flows: An Institutional View" [en línea] http://www.imf.org/ external/np/pp/eng/2012/111412.pdf. (2011a), "Recent Experiences in Managing Capital Inflows. Cross-Cutting Themes and Possible Policy Framework" [en línea] http://bit.ly/QSqrVQ.

(2011b), "The Multilateral Aspects of Policies Affecting Capital Flows" [en línea] http://bit.ly/SRk4lr.

(2010), "The Fund's Role Regarding Cross-Border Capital Flows" [en línea] http://bit.ly/Z5fLH0.

(2005), The Evaluation of the IMF's Approach to Capital Account Liberalization [en línea] http://bit.ly/VuHjz5.

Forbes, K. y otros (2012), "Bubble thy neighbor: portfolio effects and externalities from capital controls", NBER Working Paper, $\mathrm{N}^{\circ}$ 18052, Cambridge, Massachusetts, National Bureau of Economic Research

Fritz, B. y D. Magalhães Prates (2014), "The new IMF approach to capital account management and its blind spots: lessons from Brazil and South Korea", International Review of Applied Economics, vol. 28, $\mathrm{N}^{\circ} 2$, Taylor \& Francis.

Gagnon, J. y A.P. Chaboud (2007), "What can the data tell us about carry trades in Japanese Yen?", FRB International Finance Discussion Papers, $\mathrm{N}^{\circ}$ 899, Washington, D.C., Junta de Gobernadores de la Reserva Federal.

Gallagher, K. (2014), Countervailing Monetary Power: Emerging Markets and the Re-Regulation of Cross-Border Finance, Ithaca, Cornell University Press.

(2012), "The IMF's new view on financial globalization: a critical assessment", Issues in Brief, No. 2, Boston, Centro Frederick S. Pardee para el estudio del futuro a más largo plazo.

Gallagher, K., S. Griffith-Jones y J.A. Ocampo (eds.) (2012), Regulating Global Capital Flows for Long-Run Development, Boston, Centro Frederick S. Pardee para el estudio del futuro a más largo plazo.

Hennings, K. y F.A. Rocha (2013), "Evolution of Capital Flows to the Brazilian Economy after 2008", Banco Central del Brasil, inédito.

Herr, H. y J. Priewe (2006), "Capital Account Regimes and Monetary Policy in Developing Countries. Liberalization with Regulation", Berlín, inédito.

Huh, I., J. An y D. Yang (2013), "The effect of Korea's macroprudential measures", World Economy Update, vol. 3, $\mathrm{N}^{\circ} 3$, Seúl, Korea Institute for International Economic Policy.

Jeanne, O. (2012), "Capital flow management", American Economic Review, vol. 102, $\mathrm{N}^{\circ} 3$, Nashville, Tennessee, American Economic Association.

Jeanne, O., A. Subramanian y J. Williamson (2012), Who Needs to Open the Capital Account?, Washington, D.C., Peterson Institute for International Economics.

Jinjarak, Y., I. Noy y H. Zheng (2013), "Capital controls in Brazil - Stemming a tide with a signal?", NBER Working Paper, $\mathrm{N}^{\circ}$ 19205, Cambridge, Massachusetts, National Bureau of Economic Research.

Johnson, C. (2007), "Trading volume. Strong start to 2007 in most markets", Futures Industry Magazine, mayo-junio.

Jong-Heon, L. (2008), "South Korean firms suffering cash crunch", UPI Asia, 18 de noviembre.

Jun, K. e I. Nam (2012), "South Korea tightens FX rules to temper won surge", The Wall Street Journal, 26 de noviembre.

Kaltenbrunner, A. (2010), "International Financialization and Depreciation: The Brazilian Real in the international financial crisis", Competition and Change, vol. 14, $\mathrm{N}^{\circ} 3$-4, SAGE.

Kaltenbrunner, A. y J.P. Painceira (2013), The Impossible Trinity on "Steroids": Inflation Targeting and Exchange Rate Management in Emerging Markets, Leeds University Business School.

Kim, S. y D. Yong Yang (2010), "Managing capital flows. The case of the Republic of Korea", Managing Capital Flows. The Search for a Framework, M. Kawai y M.B. Lamberte (eds.), Cheltenham, Edward Elgar/Instituto del Banco Asiático de Desarrollo. 
Klein, M.W. (2012), "Capital Controls: Gates versus Walls", Brookings Papers on Economic Activity [en línea] http://www. brookings.edu/ /media/Projects/BPEA/Fall\%202012/2012b_ Klein.pdf.

Klitgaard, T. (2004), "Exchange rate changes and net positions of speculators in the futures market", Economic Policy Review, vol. 10, $\mathrm{N}^{\circ} 1$, Nueva York, Banco de la Reserva Federal de Nueva York, mayo.

Korinek, A. (2008), Regulating Capital Flows to Emerging Markets: an externality view, Universidad de Maryland [en línea] http://siteresources.worldbank.org/INTFR/Resources/ KorinekCapitalFlows092908.pdf.

Kose, A. y otros (2006), "Financial flobalization: a reappraisal", NBER Working Paper, $\mathrm{N}^{\circ}$ 12484, Cambridge, Massachusetts, National Bureau for Economic Research.

Magud, N., C.M. Reinhart y K. Rogoff (2011), "Capital controls: myth and reality. A portfolio balance approach", NBER Working Paper, $\mathrm{N}^{\circ} 16805$, Cambridge, Massachusetts, National Bureau of Economic Research.

Mihaljek, D. y F. Packer (2010), "Derivatives in emerging markets", BIS Quarterly Review, Basilea, Banco de Pagos Internacionales, diciembre.

Mohan, R. (2012), "Capital account management: the need for a new consensus", Regulating Global Capital Flows for LongRun Development, K. Gallagher y otros (eds.), Boston, Centro Frederick S. Pardee para el estudio del futuro a más largo plazo.

Mussa, M. y otros (1998), "Capital account liberalization: theoretical and practical aspects", IMF Occasional Paper, $\mathrm{N}^{\circ} 172$, Washington, D.C., Fondo Monetario Internacional.

Neely, Ch. (1999), "An introduction to capital controls", Review, Banco de la Reserva Federal de Saint Louis, noviembrediciembre.

Nogueira Batista Jr., P. (2012), "The IMF, capital account regulation, and emerging market economies", Regulating Global Capital Flows for Long-Run Development, K. Gallagher y otros (eds.), Boston, Centro Frederick S. Pardee para el estudio del futuro a más largo plazo.

Ocampo, J.A. (2012), "The case for and experience with capital account regulations", Regulating Global Capital Flows for Long-Run Development, K. Gallagher y otros (eds.), Boston, Centro Frederick S. Pardee para el estudio del futuro a más largo plazo.

OCDE (Organización para la Cooperación y el Desarrollo Económicos) (2009), "Code of Liberalization of Capital Movements and of Current Invisible Operations" [en línea] http://www.oecd.org/do cument/59/0,3343,en_2649_34887_1826559_1_1_1_1,00.html.

Ostry, J. y otros (2011a), "Managing capital inflows: what tools to use?", IMF Staff Discussion Notes, $\mathrm{N}^{\circ} 11 / 06$, Washington, D.C., Fondo Monetario Internacional.

(2011b), "Capital controls: when and why?", IMF Economic Review, vol. 59, $\mathrm{N}^{\circ}$ 3, Washington, D.C., Palgrave Macmillan.
(2010), "Capital inflows. The role of controls", IMF Staff Position Note, $\mathrm{N}^{\circ}$ 2010/04, Washington, D.C., Fondo Monetario Internacional.

Paula, L.F. y D. Prates (2013), "Regulación de la cuenta de capital, tratados de comercio e inversión y espacio de políticas de Brasil", Regulación de la cuenta de capital y el sistema de comercio: un estudio de compatibilidad, K. Gallagher y L. Stanley (eds.), Boston, Centro Frederick S. Pardee para el estudio del futuro a más largo plazo.

Pradhan, M. y otros (2011), "Policy responses to capital flows in emerging markets", IMF Staff Discussion Notes, $\mathrm{N}^{\circ} 11 / 10$, Washington, D.C., Fondo Monetario Internacional.

Prates, D. y B. Fritz (2014), "Capital account regulation as part of the macroeconomic regime: comparing Brazil in the 1990s and 2000s", inédito.

Prates, D. y M. Cintra (2010), "The emerging-market economies in the face of the global financial crisis", The Financial and Economic Crisis of 2008-2009 and Developing Countries (UNCTAD/GDS/MDP/2010/1), S. Dullien y otros (eds.), Ginebra, Naciones Unidas.

Prates, D., A. Cunha y M.T.C. Lélis (2009a), "La gestión del régimen cambiario en Brasil", Revista CEPAL, No 99 (LC/G.2418-P), Santiago, Comisión Económica para América Latina y el Caribe (CEPAL).

(2009b), "Os determinantes das taxas de câmbio nominal e real no Brasil no período 2003-2007”, Ensaios sobre Economia Financeira, F. Ferreira y B. Meireles (orgs.), Río de Janeiro, Banco de Desarrollo del Brasil (BNDES).

Priewe, J. (2011), "Capital Account Management in Developing Countries", Ginebra, versión preliminar.

Rodrik, D. (2010), “The end of an era in finance?", Project Syndicate [en línea] http://bit.ly/XuxYxl.

(2008), "Second-best institutions", NBER Working Paper, $\mathrm{N}^{\circ} 14050$, Cambridge, Massachusetts, National Bureau of Economic Research.

(2006), "The social cost of foreign exchange reserves", International Economic Journal, vol. 20, $\mathrm{N}^{\circ} 3$, Taylor \& Francis.

Rogoff, K. y otros (2004), "Effects of financial globalization on developing countries: some empirical evidence", IMF Occasional Papers, $\mathrm{N}^{\circ} 220$, Washington, D.C., Fondo Monetario Internacional.

Ventura, A. y M. García (2009), "Mercados futuro e à vista de câmbio no Brasil: o rabo balança o cachorro", Texto para Discussão, $\mathrm{N}^{\circ}$ 563, Río de Janeiro, Departamento de Economía, Pontificia Universidad Católica de Río de Janeiro.

Williamson, J. (2005), Curbing the Boom-Bust Cycle: Stabilizing Capital Flows to Emerging Markets, Washington, D.C., Peterson Institute.

Williamson, J., S. Griffith-Jones y R. Gottschalk (2003), "Should Capital Controls Have a Place in the Future International Monetary System?" [en línea] http://bit.ly/12h2wlK. 